\title{
Generation of an Iba1-EGFP Transgenic Rat for the Study of Microglia in an Outbred Rodent Strain
}

\author{
DJonathan W. VanRyzin,, ${ }^{1}$ Sheryl E. Arambula, ${ }^{1}$ Sydney E. Ashton, ${ }^{2}$ Alexa C. Blanchard, ${ }^{1}$ \\ Max D. Burzinski, ${ }^{1}$ Katherine T. Davis, ${ }^{1}$ Serena Edwards, ${ }^{1}$ Emily L. Graham, ${ }^{1}$ Amanda Holley, ${ }^{1}$ \\ Katherine E. Kight, ${ }^{1}$ Ashley E. Marquardt, ${ }^{2}$ @Miguel Perez-Pouchoulen, ${ }^{1}{ }^{\text {Lindsay A. Pickett, }}{ }^{2}$ \\ Erin L. Reinl, ${ }^{1}$ and ${ }^{-}$Margaret M. McCarthy ${ }^{1,2}$
}

\section{https://doi.org/10.1523/ENEURO.0026-21.2021}

${ }^{1}$ Department of Pharmacology, University of Maryland School of Medicine, Baltimore, Maryland 21201 and ${ }^{2}$ Program in Neuroscience, University of Maryland School of Medicine, Baltimore, Maryland 21201

\begin{abstract}
Neuroscience has been transformed by the ability to genetically modify inbred mice, including the ability to express fluorescent markers specific to cell types or activation states. This approach has been put to particularly good effect in the study of the innate immune cells of the brain, microglia. These specialized macrophages are exceedingly small and complex, but also highly motile and mobile. To date, there have been no tools similar to those in mice available for studying these fundamental cells in the rat brain, and we seek to fill that gap with the generation of the genetically modified Sprague Dawley rat line: SD-Tg(Iba1-EGFP)Mmmc. Using CRISPR-Cas/9 technology, we knocked in EGFP to the promoter of the gene Iba1. With four male and three female founders confirmed by quantitative PCR analysis to have appropriate and specific insertion, we established a breeding colony with at least three generations of backcrosses to obtain stable and reliable Iba1EGFP expression. The specificity of EGFP expression to microglia was established by flow cytometry for CD $45^{\text {low }} / \mathrm{CD} 11 \mathrm{~b}^{+}$cells and by immunohistochemistry. Microglial EGFP expression was detected in neonates and persisted into adulthood. Blood macrophages and monocytes were found to express low levels of EGFP, as expected. Last, we show that EGFP expression is suitable for live imaging of microglia processes in acute brain slices and via intravital two-photon microscopy.
\end{abstract}

Key words: brain; EGFP; Iba1; macrophage; microglia; transgenic rat

\section{Significance Statement}

Neuroscience research in rat models has lagged compared with the mouse because of limitations in the ability to generate genetic modifications. To fill part of that gap, we have generated a transgenic rat in which the innate immune cells of the brain, microglia, express EGFP. This modification allows for isolation of microglia from other cells by flow cytometry or FACS for detailed transcriptomic and proteomic analysis. The visualization of EGFP in acute brain slices or by in vivo imaging further enhances the ability to interrogate the role of these critical cells across the life span and in health and disease.

\section{Introduction}

Microglia are the resident macrophages of the brain. Despite comprising only $10-15 \%$ of the total number of cells (Lawson et al., 1990), microglia have a drastic impact on the brain throughout the life span (Bilbo and Schwarz,

\footnotetext{
Received January 21, 2021; accepted August 11, 2021; First published August 19, 2021.

The authors declare no competing financial interests.
}

2012). During development, these specialized phagocytes act as "sculptors" of the brain by regulating cell number, coordinating synaptic connectivity, and facilitating myelination

Author contributions: J.W.V. and M.M.M. designed research; J.W.V., S.E. Arambula, S.E. Ashton, A.C.B., M.D.B., K.T.D., S.E., E.L.G., A.H., K.E.K., A.E.M., M.P.-P., L.A.P., and E.L.R. performed research; J.W.V., S.E. Arambula, S.E. Ashton, A.C.B., M.D.B., K.T.D., S.E., E.L.G., A.H., K.E.K., A.E.M., M.P.-P., L.A.P., and E.L.R. analyzed data; J.W.V. and M.M.M. wrote the paper. 
(Sierra et al., 2010; Paolicelli et al., 2011; Schafer et al., 2012; Lenz et al., 2013; Parkhurst et al., 2013; Ueno et al., 2013; Hagemeyer et al., 2017; VanRyzin et al., 2019). As the brain matures, microglia function and phenotype shift; by adulthood, microglia are tiled throughout the brain where they can effectively survey their local environment, facilitate synaptic transmission, and respond to injury (Davalos et al., 2005; Nimmerjahn et al., 2005; Wake et al., 2009; Rogers et al., 2011; Nikodemova et al., 2015).

Given the variable functional repertoire and the dynamic nature of these cells, the ability to faithfully identify and label microglia is of upmost importance to researchers. Changes in microglia function are often reflected as changes in morphology or the number at a given point in time and are often studied by examining aspects of microglia morphology in relation to other end points of interest (i.e., phagocytic cups, synaptic contacts, process motility). Identifying microglia morphology is usually accomplished by using antibody labeling for immunohistochemical analysis. Microglia express a number of proteins that can distinguish them from surrounding neural tissue, the most common being ionized calcium-binding adapter molecule 1 [lba1; also called allograft inflammatory factor-1 (Aif1)], which provides robust histologic labeling and has been widely used to good effect for many years. However, immunohistochemical analysis is severely limited as it is a postmortem method of analysis and does not allow for direct assessments of microglia function in real time.

The tools and techniques for microglia analysis have rapidly evolved for researchers using the mouse as a model organism (Guttenplan and Liddelow, 2019). These include several knock-in models such as CX3CR1 (the fractalkine receptor) being replaced with EGFP (Jung et al., 2000), EGFP driven by the endogenous Iba1 promoter (Hirasawa et al., 2005), and, more recently, EGFP driven by the microglia-specific Tmem119 gene (Kaiser and Feng, 2019). These tools have revealed unexpected roles for microglia in regulating synapses (Paolicelli et al., 2011; Schafer et al., 2012; Parkhurst et al., 2013), astroglial transitioning in the subventricular proliferative zone (Xavier et al., 2015), and distinguishing infiltration of peripheral macrophages from endogenous microglia following brain injury (Tanaka et al., 2003), to name very few. The

This research was funded by the Dean's Office, University of Maryland School of Medicine; and by Department of Health and Human Services National Institutes of Health National Institute of Mental Health Grants R01MH-52716 and R01-MH-091424, National Institute on Drug Abuse Grant R01DA-039062, and Eunice Kennedy Shriver National Institute of Child Health and Human Development Grant P01-HD-085928 to M.M.M.

Acknowledgements: We thank the Confocal Microscopy Core Facility at the University of Maryland School of Medicine for use of confocal microscopy. We also thank the University of Maryland Marlene and Stewart Greenebaum Comprehensive Cancer Center Flow Cytometry Shared Service for flow cytometry analyses.

Correspondence should be addressed to Margaret M. McCarthy at mmccarthy@som.umaryland.edu.

https://doi.org/10.1523/ENEURO.0026-21.2021 Copyright @ 2021 VanRyzin et al.

This is an open-access article distributed under the terms of the Creative Commons Attribution 4.0 International license, which permits unrestricted use, distribution and reproduction in any medium provided that the original work is properly attributed. development of comparable resources for rats has been minimal and thereby hampered progress in this valuable animal model.

Rats provide some distinct advantages over the mouse, not the least of which is physical size, which can be a limiting factor when working with very young animals or collecting small tissue samples for downstream processing [e.g., flow cytometry, fluorescence activated cell sorting (FACS), proteomics]. Many laude the rat for superior cognitive ability and social behavior complexity (Ellenbroek and Youn, 2016), and, although this notion has been challenged (Jaramillo and Zador, 2014), there is still much to understand given the importance of microglia in regulating these behavioral domains (Frost and Schafer, 2016). Rats also exhibit some behaviors not readily apparent in the mouse, for example, juvenile rough-and-tumble play (VanRyzin et al., 2019). Many sex differences in the rat brain are determined by the developmental actions of microglia (Lenz and Nelson, 2018), but a similar relationship has not yet been established in the mouse.

To address this shortcoming and provide a resource for investigators wishing to study microglia while capitalizing on the advantages of using a rat model, we contracted the design and development of a novel Iba1-EGFP transgenic rat. We show that EGFP expression is robust, highly specific to microglia in the brain, and is suitable for cellsorting and live-imaging studies.

\section{Materials and Methods}

\section{Generation and validation of SD-Tg (Iba1-EGFP) Mmmc transgenic rats}

Applied StemCell was contracted to generate the Iba1EGFP knock-in rat model using CRISPR/Cas9 technology in the Sprague Dawley rat strain. The donor construct inserted consisted of the EGFP coding sequence (minus the first ATG), followed by the 22 aa sequence of the porcine teschovirus-1 2A (P2A) self-cleaving peptide and then the first exon of the rat Iba1 gene immediately downstream of the translational start site. Guide RNA candidates targeting the Iba1 gene just downstream of the translational start site were prepared via in vitro transcription from a T7 promoter and individually tested for efficiency in Sprague Dawley embryos. The guide RNA that was used demonstrated $100 \%$ efficiency and had the following sequence: 5'-TACCCTGCAAATCCTTGCTCTGG$3^{\prime}$. Microinjected embryos were implanted into Sprague Dawley surrogate dams and the resulting pups were screened for site-specific insertion of EGFP sequence via PCR. Of 34 pups screened, 7 were positive for EGFP sequence with the correct $5^{\prime}$ and $3^{\prime}$ insertion sites at the endogenous Iba1 sequence. PCR products from these animals were sequenced to further confirm site-specific insertion of EGFP downstream of the Iba1 translational start site, the formation of correct junctions, and the fidelity of the sequence contained within the insertion. Two heterozygous male and three heterozygous female founder animals were shipped to the University of Maryland School of Medicine and were maintained on a $12 \mathrm{~h}$ reverse light/dark cycle with ad libitum access food and 
Table 1: List of RNA sequences and primers

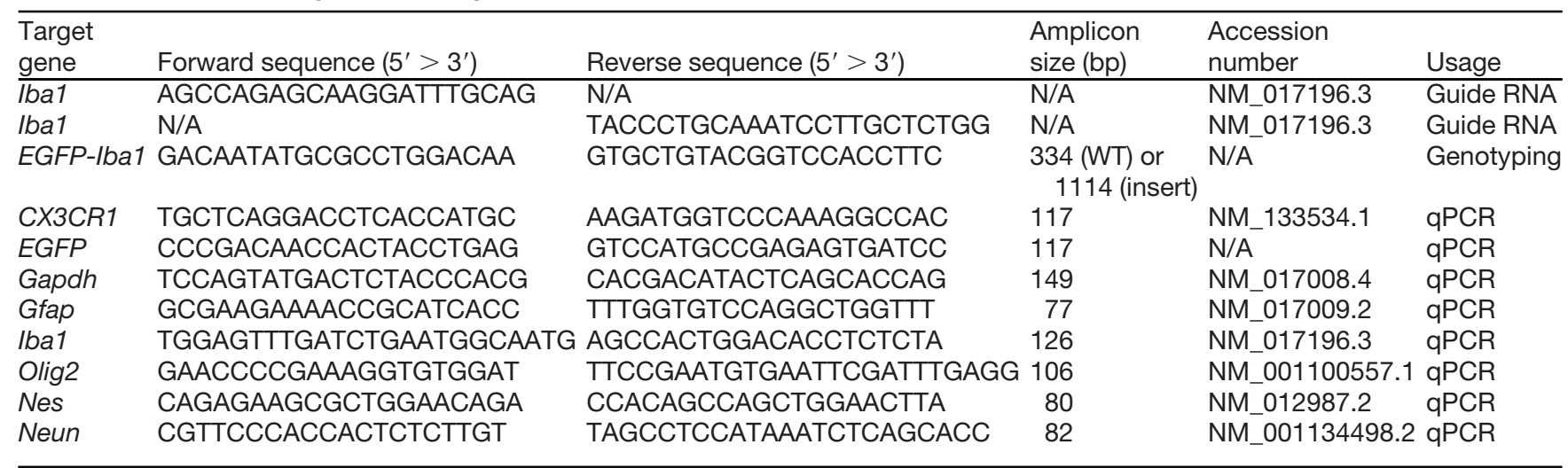

N/A, Not applicable.

water. Animals were mated in our facility, and pregnant females allowed to deliver naturally with the day of birth designated as postnatal day 0 (P0). Male and female F2 and F3 offspring of founder animals were used in these studies. All animal procedures were performed in accordance with the regulations of the Animal Care and Use Committee at the University of Maryland School of Medicine. This transgenic line has been registered with the Medical College of Wisconsin Rat Resource Center as SD-Tg(lba1-EGFP)Mmmc.

\section{Genotyping}

Genotyping of Iba1-EGFP offspring was performed using MyTaq Extract-PCR reagents (Meridian Bioscience). Tail snips taken from pups during the first 5 postnatal days or ear clips from adult animals were used to provide DNA for genotyping. Tissue homogenates were diluted 1:100 in doubledistilled $\mathrm{H}_{2} \mathrm{O}$ and were used in a PCR containing $200 \mathrm{~nm}$ each primer, and thermocycled through $95^{\circ} \mathrm{C}$ for $60 \mathrm{~min}, 55^{\circ} \mathrm{C}$ for $30 \mathrm{~s}$, and $72^{\circ} \mathrm{C}$ for $90 \mathrm{~s}$ for 34 cycles. PCR primers for genotyping were designed to target the $5^{\prime}$ upstream regulatory sequence of the endogenous $I b a 1$ gene and the Iba1 coding sequence, and span the insertion site of the EGFP sequence (Integrated DNA Technologies; Table 1). Thus, both the wildtype Iba1 allele and the EGFP insertion were detected as bands of 334 and $1114 \mathrm{bp}$, respectively. Genotyping was confirmed and is commercially available from TransnetYX.

\section{Western blot}

Total protein was isolated from cortical tissue of $\mathrm{EGFP}^{+/+}$, $\mathrm{EGFP}^{-/+}$, and $\mathrm{EGFP}^{-/-}$(wild-type) rats at $\mathrm{P} 18$ by homogenizing in $10 \mathrm{~mm}$ Tris- $\mathrm{HCl}, \mathrm{pH} 7.6 / 150 \mathrm{~mm} \mathrm{NaCl} /$ $1 \%$ Nonidet P-40/1\% sodium deoxycholate, with protease and phosphatase inhibitors (Sigma-Aldrich). For each sample, $30 \mu \mathrm{g}$ of cortical protein homogenate was resolved on a $12 \%$ Bis-Tris polyacrylamide gel (NuPage, Thermo Fisher Scientific) under reducing and denaturing conditions, and transferred to PVDF membrane. Membranes were blocked with Odyssey Blocking Buffer (LI-COR) diluted 1:1 with Trisbuffered saline (TBS), $\mathrm{pH} 7.4$, and incubated overnight at $4^{\circ}$ $\mathrm{C}$ with primary antibodies diluted in a 1:1 solution of Blocking Buffer/TBS-0.01\% Tween. The primary antibodies used were chicken-anti-GFP (1:4000; Thermo Fisher Scientific) and mouse anti-Gapdh (1:5000; Abcam). After washing in TBS-0.1\% Tween, membranes were incubated in 1:1 Blocking Buffer-TBS-Tween/0.02\% SDS containing secondary antibodies (both diluted 1:10,000; IRDye 800 donkey-anti-chicken and IRDye 680 goat-anti-mouse IgG, LI-COR). Membranes were imaged on an Odyssey CLx Infrared Imaging System (LI-COR).

\section{Flow cytometry}

Animals were deeply anesthetized with Fatal Plus (Vortech Pharmaceuticals) and were transcardially perfused with ice-cold PBS, $0.1 \mathrm{M}, \mathrm{pH} 7.4$, until the perfusate was clear. Intracardiac blood was collected, washed with PBS, resuspended in an ammonium chloride red blood cell lysis buffer for $10 \mathrm{~min}$, and centrifuged to obtain a clear cell pellet before antibody labeling. Neonatal (P7) brains, spinal cords, and dorsal root ganglia were removed and dissociated with the Neural Tissue Dissociation Kit $P$ (Miltenyi Biotec). Adult $(\mathrm{P} 60+)$ brains were dissociated with $1 \mathrm{mg} / \mathrm{ml}$ collagenase-D (Sigma-Aldrich) and $0.25 \mathrm{mg} / \mathrm{ml}$ DNase I (Sigma-Aldrich) in RPMI solution (Thermo Fisher Scientific) for $20 \mathrm{~min}$. Cells were washed in RPMI solution, resuspended in 37\% Percoll (Sigma-Aldrich), and centrifuged at $1200 \times g$ for $15 \mathrm{~min}$ to separate the myelin debris layer. Both neonatal and adult brain homogenates were washed with ice-cold FACS buffer ( $2 \%$ bovine serum albumin, 2 mm EDTA in PBS) before antibody labeling.

Blood and brain samples were blocked with anti-CD32 (1:100; clone D34-485, BD Biosciences) and stained with Fixable Viability Dye eFluor 780 (Thermo Fisher Scientific). To identify microglia, cells were labeled with anti-CD11bPE (1:200; clone WT.5, BD Biosciences) and anti-CD45AF700 (1:200; clone OX-1, BD Biosciences) antibodies in FACS buffer. Cells were washed and analyzed on an LSRII flow cytometer (BD Biosciences) with FACSDiva software.

To characterize peripheral immune cells, cells were labeled with anti-RT1B BV421 (1:200; clone OX-6, BD Biosciences), anti-CD3 PE (1:200; clone 1F4, BD Biosciences), anti-CD45R Pe-Cy7 (1:200; clone HIS24, Thermo Fisher Scientific), antiCD11b APC (1:200; clone WT.5, BD Biosciences), anti-CD45 
AL700 (1:200; clone OX-1, BD Biosciences), and anti-rat granulocyte biotin (1:200; clone His48, Thermo Fisher Scientific) followed by streptavidin PerCp-Cy5.5 (1:500; Thermo Fisher Scientific) in FACS buffer. Cells were washed and analyzed on a Cytek Aurora flow cytometer (CYTEK). Data were analyzed using FCS Express 6 (De Novo Software) and FlowJo X (FlowJo) software.

\section{Cell sorting}

Samples were prepared as described for flow cytometry, without the addition of antibody or dye labeling and sorted using an Aria II Cell Sorter (BD Biosciences) with a $100 \mu \mathrm{m}$ pore size. Samples were gated for EGFP expression and run until 50,000 $\mathrm{EGFP}^{+}$cells were collected. Cells were then resuspended in Qiazol (Qiagen) and stored at $-80^{\circ} \mathrm{C}$ until processed.

\section{RNA isolation, cDNA synthesis, and quantitative PCR}

Total RNA was extracted using the protocol for fatty tissues from the RNeasy Handbook for Mini Kit (Qiagen). Single-stranded cDNA synthesis was performed with $200 \mathrm{ng}$ of RNA input using the high-capacity cDNA Reverse Transcription Kit (Thermo Fisher Scientific), and samples were stored at $-20^{\circ} \mathrm{C}$ until use. Quantitative PCR (qPCR) was performed using an Applied Biosystems ViiA7 PCR System (Thermo Fisher Scientific) with the following cycling parameters: $50^{\circ} \mathrm{C}$ for $2 \mathrm{~min}, 95^{\circ} \mathrm{C}$ for $10 \mathrm{~min}$, followed by 40 cycles of $95^{\circ} \mathrm{C}$ for $15 \mathrm{~s}$ and $60^{\circ} \mathrm{C}$ for 1 min. Primers (Integrated DNA Technologies; Table 1) were designed using Primer3 software, and primer efficiency was determined through the use of serial dilutions. Samples were run in triplicate, cycle threshold (Ct) values for the gene of interest were normalized to the $\mathrm{Ct}$ for Gapdh $(\Delta-\mathrm{Ct})$, and relative data were determined by the $\Delta \Delta$-Ct method (Schmittgen and Livak, 2008).

\section{Immunohistochemistry}

Animals were deeply anesthetized with Fatal Plus (Vortech Pharmaceuticals) and transcardially perfused with PBS, $0.1 \mathrm{M}, \mathrm{pH} 7.4$, followed by $4 \%$ paraformaldehyde (PFA; $4 \%$ in PBS), pH 7.2. Brains were removed and postfixed for $24 \mathrm{~h}$ in $4 \%$ PFA at $4^{\circ} \mathrm{C}$, then kept in $30 \%$ sucrose at $4^{\circ} \mathrm{C}$ until fully submerged. Coronal sections ( $45 \mu \mathrm{m}$ thick) were cut on a cryostat (model CM2050S, Leica) and directly mounted onto slides. Slide-mounted sections were washed in PBS, blocked with $5 \%$ normal goat serum (NGS) in PBS $+0.4 \%$ Triton $X-100$ (PBS-T) for $1 \mathrm{~h}$, and incubated with anti-GFP (1:1000; catalog \#ab13970, Abcam) and anti-lba1 (1:1000; catalog \#019-19741, Wako) in 2\% NGS in PBS-T overnight. The next day, slides were incubated with Alexa Fluor 488 (1:500; Thermo Fisher Scientific) and Alexa Fluor 594 (1:500; Thermo Fisher Scientific) in PBS-T for $2 \mathrm{~h}$, washed and stained with Hoechst 33342 (1:3000; catalog \#H3570, Thermo Fisher Scientific) for $10 \mathrm{~min}$, and coverslipped with ProLong Diamond Antifade (Thermo Fisher Scientific).

\section{Microscopy and colocalization analysis}

Wide-field fluorescence images were captured on a Keyence BZ-X700 microscope using a 10× objective [0.45 numerical aperture (NA)] and $20 \times$ objective $(0.75 \mathrm{NA})$ and BZ-X Viewer software. For colocalization analysis, single field-of-view images were taken at $20 \times$ magnification using $0.4 \mu \mathrm{m} z$-steps through the entire tissue thickness. Subsequent maximum intensity projections were used to quantify microglia as $\mathrm{Iba} 1^{+}$and $\mathrm{EGFP}^{+}$using the cell counter plugin in Fiji (Schindelin et al., 2012).

\section{Slice preparation and live imaging}

The brain was rapidly dissected out from a P7 rat pup following decapitation and immediately placed in ice-cold artificial CSF (aCSF) containing (in $\mathrm{mm}$ ) $125 \mathrm{NaCl}, 2.5 \mathrm{KCl}$, $1 \mathrm{MgCl}_{2}, 1.25 \mathrm{NaH}_{2} \mathrm{PO}_{4}, 2 \mathrm{CaCl}_{2}, 25 \mathrm{NaHCO}_{3}, 25$ glucose, and 75 sucrose, pH 7.4 (Dailey et al., 2013; Huang et al., 2018). Coronal sections ( $\sim 0.5 \mathrm{~mm})$ were cut using a Zivic Brain Slicer Matrix on ice. A section was transferred to a MaTek glass bottom microwell dish $(35 \mathrm{~mm}$ dish, no. 1.5 coverslip) containing room temperature aCSF (in mM: $125 \mathrm{NaCl}, 2.5 \mathrm{KCl}, 1 \mathrm{MgCl}_{2}, 1.25 \mathrm{NaH}_{2} \mathrm{PO}_{4}, 2 \mathrm{CaCl}_{2}, 25$ $\mathrm{NaHCO}_{3}$, and 10 glucose, $\mathrm{pH}$ 7.4). Confocal fluorescent images using a $1 \mu \mathrm{m} z$-step across $10 \mu \mathrm{m}$ of tissue for a single field of view were acquired once per minute for a total of 20 min with a Nikon A1 microscope equipped with a 488 laser using an Apo 60× Oil objective (1.4 NA). ATP (Sigma-Aldrich) was bath applied (1 $\mathrm{mm}$ in aCSF) after 4 min of baseline imaging. The motion of 10 microglial processes from five microglia was analyzed using the MTrackJ plugin (https://imagej.net/MTrackJ) for ImageJ (Meijering et al., 2012).

\section{Intravital two-photon microscopy}

Neonatal $(\mathrm{P} 14)$ Iba1-EGFP ${ }^{+/+}$rats and adult B6.129P-

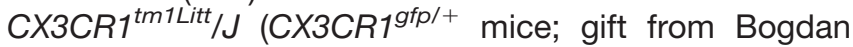
Stoica, Department of Anesthesiology, University of Maryland School of Medicine, Baltimore, MD) were anesthetized with ketamine $(85 \mathrm{mg} / \mathrm{kg})$ and xylazine $(13 \mathrm{mg} /$ $\mathrm{kg}$ ), and maintained on a heating pad. A thin skull preparation was performed as previously described (Roth et al., 2014). A metal bracket was secured over the parietal lobe, and the skull bone was thinned to $\sim 30-60 \mu \mathrm{m}$. Intravital two-photon microscopy was performed using a two-photon microscope (SP5 II, Leica) equipped with a $20 \times$ waterdipping objective (1.0 NA), a PMT-ready Objective Inverter (LSM TECH), and a Coherent Chameleon Laser tuned to $880 \mathrm{~nm}$ for GFP (provided by Alan Faden, the University of Maryland Center for Shock Trauma and Anesthesiology Research, Baltimore, MD). 3D time-lapse movies were captured in $z$-stacks of 10-15 planes (step size, $3 \mu \mathrm{m} ; 3 \times$ zoom) at $\sim 30 \mathrm{~s}$ intervals. Image analysis was performed using Imaris (Oxford Instruments) and ImageJ.

\section{Quantification and statistical analysis}

Statistical analysis was performed using $\mathrm{R}$ (version 3.4.4; R Core Team, 2018) or GraphPad Prism 8. See Table 2 for details regarding specific data or comparisons 
A

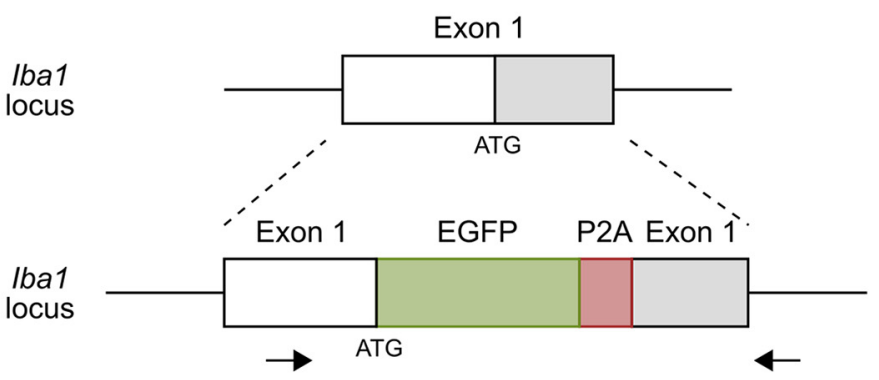

B

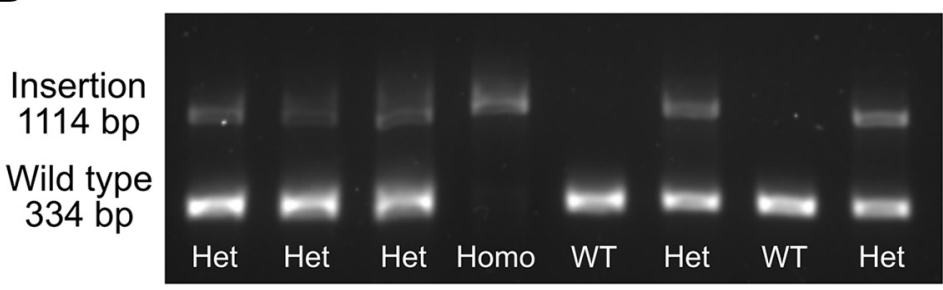

C

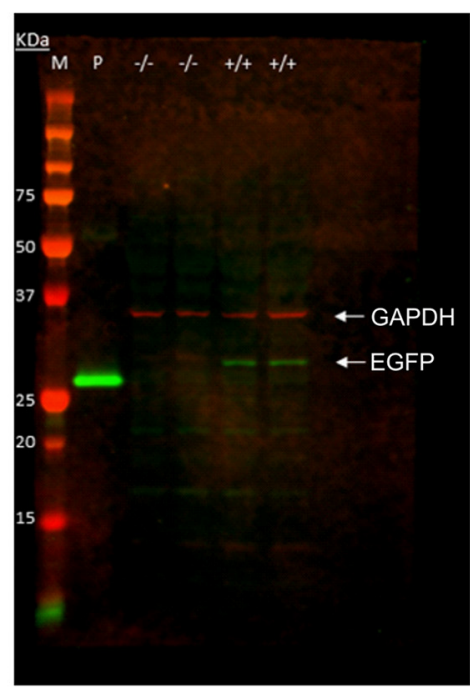

D

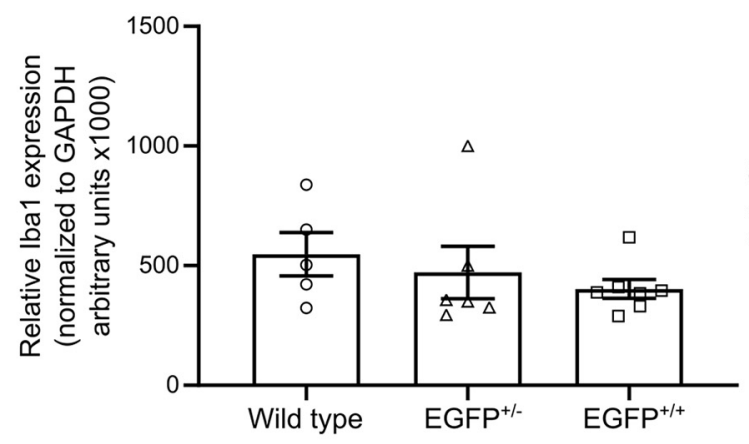

E

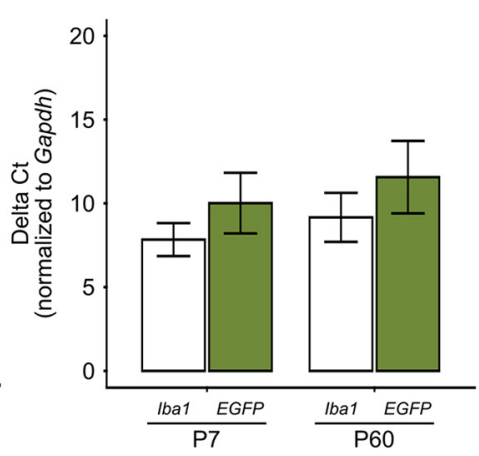

Figure 1. Generation of Iba1-EGFP knock-in rat. $\boldsymbol{A}$, Schematic of exon 1 of the lba1 gene (top) and the EGFP-P2A insertion (bottom). The black bar indicates the transcription start site (ATG), and the gray region represents the protein-coding region of the exon. The EGFP (green) and P2A (red) sequences were inserted at the transcription start site of exon 1. B, Representative image of a genotyping gel showing the presence of two distinct bands. The lower band (334 bp) is the amplification of the wild-type allele, while the upper band (1114 bp) is the amplification of the EGFP-P2A-containing allele. C, Representative Western blot image for GAPDH protein (top band; red) and EGFP protein (bottom band; green). Lane M, Protein marker (various sizes labeled on the left); lane P, $30 \mathrm{ng}$ of purified recombinant EGFP protein; lane $-/-, 30 \mu \mathrm{g}$ of total protein from cortical homogenates of EGFP ${ }^{-/-}$rats; lane $+/+$, $30 \mu \mathrm{g}$ of total protein from cortical homogenates of EGFP ${ }^{+/+}$rats. $\boldsymbol{D}$, Quantification of Iba1 protein expression in wild-type, EGFP ${ }^{+/-}$, and EGFP ${ }^{+/+}$littermates. E, qPCR quantification of $I b a 1$ and EGFP transcripts in $\mathrm{EGFP}^{+/+}$rats at various time points during development. Open symbols in $\boldsymbol{D}$ represent individual animal datapoints.

(e.g., descriptive statistics, test used, $n$, which are referenced in text using superscript letters). Analyses were considered significant at $p \leq 0.05$.

\section{Results}

\section{Generation of SD-Tg (Iba1-EGFP)Mmmc transgenic rats}

We sought to generate a model in which EGFP was expressed under control of the endogenous Iba1 promoter without altering the endogenous Iba1 protein. To this end, the EGFP coding sequence and $P 2 A$ linker sequence were inserted immediately following the translation start codon in the first exon of rat $I b a 1$ and upstream of the remainder of the endogenous Iba1 gene (Fig. 1A). This results in the expression of both EGFP and Iba1 in a single
mRNA transcript under control of the endogenous regulatory sequence of the $I b a 1$ gene. Ribosomal skipping at the $P 2 A$ sequence results in a modified EGFP that contains 17 aa of the P2A peptide at the $C$ terminus and Iba1 as the translation products. For genotyping, we designed forward and reverse primers for PCR that spanned exon 1. The resulting PCR products confirmed the presence of the EGFP/P2A insertion in homozygous (EGFP ${ }^{+/+}$) and heterozygous (EGFP ${ }^{+/-}$) offspring, while the insert was absent in wild-type (EGFP ${ }^{-/}$) littermates (Fig. 1B). To verify whether the EGFP/P2A insertion altered expression of the Iba1 gene, we first used Western blot to determine the presence of unspliced EGFP-P2A-lba1 fusion proteins in cortical tissue homogenates. As expected anti-GFP antibody detected a band of $\sim 35 \mathrm{kDa}$, which corresponds to the EGFP protein with the 17 aa P2A peptide on the $C$ 
Table 2: Summary of descriptive statistics and statistical analyses

\begin{tabular}{|c|c|c|c|c|c|c|}
\hline Line & Data structure & Type of test & Description of data or analysis & Test value & $p$ Value & Mean \pm SD \\
\hline$a$ & Normal distribution & One-way ANOVA & $\begin{array}{l}\text { Iba1 protein, WT }(n=5) \text { vs Het }(n=6) \text { vs } \\
\text { Homo }(n=7)\end{array}$ & $F_{(2,15)}=0.7877$ & $p=0.4728$ & $\begin{array}{l}\text { WT: } 547,400 \pm 202,011 \\
\text { Het: } 471,500 \pm 268,511 \\
\text { Homo: } 402,143 \pm 104,266\end{array}$ \\
\hline b & Normal distribution & Welch's $t$ test & $\begin{array}{l}\text { qPCR quantification }(\Delta \mathrm{Ct}) \text {; Iba1 expression } \\
\quad \text { at P7 }(n=15) \text {, and P60 }(n=6)\end{array}$ & $t_{(6.9003)}=-2.0425$ & $p=0.081$ & $P 7: 7.84 \pm 0.99$ P60: $9.16 \pm 1.46$ \\
\hline c & Normal distribution & Welch's $t$ test & $\begin{array}{l}\text { qPCR quantification }(\Delta \mathrm{Ct}) \text {; EGFP expression } \\
\text { at P7 }(n=15) \text {, and P60 }(n=6)\end{array}$ & $t_{(7.9695)}=-1.5523$ & $p=0.1593$ & $\mathrm{P} 7: 10.01 \pm 1.81 \mathrm{P} 60: 11.56 \pm 2.16$ \\
\hline \multirow[t]{2}{*}{ d } & Normal distribution & Welch's $t$ test & $\begin{array}{l}\text { Median fluorescence intensity; Het }(n=4) \\
\text { vs Homo }(n=6)\end{array}$ & $t_{(7.5763)}=-1.8756$ & $p=0.09963$ & Het: $623.25 \pm 119.96$ Homo: $843.67 \pm 247.54$ \\
\hline & Normal distribution & One-sample $t$ test & $\begin{array}{l}\text { qPCR quantification }(\Delta \Delta \mathrm{Ct}) ; \mathrm{EGFP}^{+/+} \text {sorted } \\
\text { cells }(n=3) \text { vs normalized value }=0\end{array}$ & & & \\
\hline e & & & Iba1 & $t_{(2)}=-11.036$ & $p=0.00811$ & $19.84 \pm 8.67$ \\
\hline$f$ & & & CХ3CR1 & $t_{(2)}=-63.772$ & $p=0.0002458$ & $37.35 \pm 3.57$ \\
\hline g & & & Nes & $t_{(2)}=6.8055$ & $p=0.02092$ & $0.40 \pm 0.09$ \\
\hline $\mathrm{h}$ & & & Gfap & $t_{(2)}=55.708$ & $p=0.0003221$ & $0.08 \pm 0.03$ \\
\hline i & & & Olig2 & $t_{(2)}=11.419$ & $p=0.007582$ & $0.04 \pm 0.004$ \\
\hline j & & & NeuN & $t_{(2)}=3.0812$ & $p=0.09116$ & $0.28 \pm 0.17$ \\
\hline $\mathrm{k}$ & Normal distribution & Unpaired $t$ test & $\begin{array}{l}\text { Median fluorescence intensity; blood }(n=9) \\
\quad \text { vs brain }(n=9), \text { P7 }\end{array}$ & $t_{(17)}=2.2865$ & $p \leq 0.0001$ & Blood: $123.56 \pm 16.49$ Brain: $755.50 \pm 227.59$ \\
\hline I & Normal distribution & Unpaired $t$ test & $\begin{array}{l}\text { Median fluorescence intensity; blood }(n=6) \\
\text { vs brain }(n=6), \text { P60 }\end{array}$ & $t_{(10)}=5.5178$ & $p=0.0003$ & Blood: $758.17 \pm 161.10$ Brain: $9690.2 \pm 3961.8$ \\
\hline \multirow[t]{2}{*}{$\mathrm{m}$} & Normal distribution & Unpaired $t$ test & CD45 high $\mathrm{EGFP}^{+}$in brain and blood & $t_{(4)}=5.050$ & $p=0.0072$ & $\begin{array}{l}\text { Blood: } 15.87 \pm 4.704 \\
\quad \text { Brain: } 52.23 \pm 11.55\end{array}$ \\
\hline & Normal distribution & Unpaired $t$ test & EGFP $^{+}$population in brain $(n=3)$ and blood $(n=3)$ & & & \\
\hline $\mathrm{n}$ & & & B cells & $t_{(4)}=2.825$ & $p=0.0476$ & Blood: $11.81 \pm 7.18$ Brain: $0.1 \pm 0.17$ \\
\hline o & & & T cells & $t_{(4)}=4.085$ & $p=0.0150$ & Blood: $0.13 \pm 0.06$ Brain: $0.95 \pm 0.34$ \\
\hline $\mathrm{p}$ & & & Myeloid/macrophage & $t_{(4)}=32.20$ & $p=<0.0001$ & Blood: $2.92 \pm 0.6$ Brain: $61.67 \pm 3.1$ \\
\hline$q$ & & & Monocyte & $t_{(4)}=3.479$ & $p=0.0254$ & $\begin{array}{l}\text { Blood: } 51.93 \pm 15.12 \\
\quad \text { Brain: } 18.97 \pm 6.39\end{array}$ \\
\hline r & & & Other & $t_{(4)}=1.979$ & $p=0.1189$ & Blood: $28.1 \pm 10.91$ Brain: $15.03 \pm 3.42$ \\
\hline s & Normal distribution & Unpaired $t$ test & $\begin{array}{l}\text { Myeloid cell/macrophage EGFP }{ }^{+} \text {in brain } \\
\qquad(n=3) \text { and blood }(n=3)\end{array}$ & $t_{(4)}=3.999$ & $p=0.0161$ & Blood: $62.17 \pm 9.767$; Brain: $85.37 \pm 2.359$ \\
\hline \multirow[t]{2}{*}{$\mathrm{t}$} & Normal distribution & Unpaired $t$ test & Monocyte EGFP ${ }^{+}$in brain $(n=3)$ and blood $(n=3)$ & $t_{(4)}=2.568$ & $p=0.0621$ & $\begin{array}{l}\text { Blood: } 39.97 \pm 13.79 \\
\text { Brain: } 69.43 \pm 14.31\end{array}$ \\
\hline & & & $\begin{array}{l}\text { Iba } 1^{+} / \mathrm{GFP}^{+} \text {colocalization; Het }(n=4) \text { vs } \\
\text { Homo }(n=6)\end{array}$ & & & \\
\hline u & & & Prefrontal cortex & & & Het: $93.97 \pm 12.06 \%$ Homo: $100 \pm 0 \%$ \\
\hline v & & & Nucleus accumbens & & & Het: $91.59 \pm 3.69 \%$ Homo: $98.96 \pm 2.55 \%$ \\
\hline w & & & Hippocampus & & & Het: $92.59 \pm 9.19 \%$ Homo: $95.34 \pm 8.42 \%$ \\
\hline$x$ & & & Amygdala & & & Het: $91.39 \pm 5.05 \%$ Homo: $100 \pm 0 \%$ \\
\hline
\end{tabular}

Het, Heterozygous; Homo, homozygous.

terminus that was present in $\mathrm{EGFP}^{+/+}$rats, but not in $\mathrm{EGFP}^{-1-}$ rats. Higher-molecular-weight bands corresponding to EGFP-P2A-lba1 fusion protein, which is predicted at $\sim 52 \mathrm{kDa}$, were not detected. We then quantified lba1 protein and found no difference in lba1 levels across genotypes, demonstrating that the expression of lba1 protein in transgenic animals is comparable to endogenous lba1 expression in WT rats (Fig. $1 D^{\mathrm{a}}$ ). Finally, we quantified Ibal and EGFP mRNA by $\mathrm{qPCR}$ at both P7 and P60 to determine whether the gene expression varied with age. The mRNA levels of both Iba1 and eGFP were comparable at both ages $\left(p=0.08^{\mathrm{b}}\right.$ for Iba1; $p=0.16^{\mathrm{C}}$ for EGFP; Fig. $1 E$ ), indicating that the transgene is robustly expressed into early adulthood.

\section{Flow cytometry validation of EGFP ${ }^{+}$cells}

To determine whether $\mathrm{EGFP}^{+}$cells expressed markers commonly associated with microglia, we used flow cytometry to analyze the expression of CD45 and CD11b in cells acutely isolated from the brains of P7 EGFP ${ }^{+/+}$ or $\mathrm{EGFP}^{-1-}$ (wild-type) littermates (Fig. 2A,B). In whole-brain homogenates, $\sim 9.8 \%$ of cells were $\mathrm{EGFP}^{+}$from $\mathrm{EGFP}^{+/+}$animals compared with $0.1 \%$ of cells from wild-type animals (Table 3 ). Furthermore, 95.3\% of the EGFP ${ }^{+}$cells were identified as CD11b ${ }^{+}$/ CD45 ${ }^{\text {int }}$, consistent with microglia-like patterns of expression (Fig. 2A, Table 3 ).

We then analyzed the data in reverse, first gating for $\mathrm{CD}_{11 \mathrm{~b}}{ }^{+} / \mathrm{CD} 45^{\text {int }}$ cells and then by EGFP revealing that $\sim 10 \%$ of all cells were $\mathrm{CD}_{11} \mathrm{~b}^{+} / \mathrm{CD} 45^{\text {int }}$ in $\mathrm{EGFP}^{+/+}$animals similar to age-matched wild types (8.3\% of cells). Further analysis of the $\mathrm{CD} 11 \mathrm{~b}^{+} / \mathrm{CD} 45^{\text {int }}$ fraction found that $94.9 \%$ were $\mathrm{EGFP}^{+}$in EGFP ${ }^{+/+}$compared with $0.7 \%$ in wild-type animals (Fig. 2B, Table 3). As the EGFP gene dosage may affect the relative fluorescence intensity between $\mathrm{EGFP}^{+/+}$and $\mathrm{EGFP}^{+/-}$animals, we compared the median fluorescence intensity (MFI) of heterozygous and homozygous littermates at P7. Overall, the MFI values 
Neonate (P7)
A
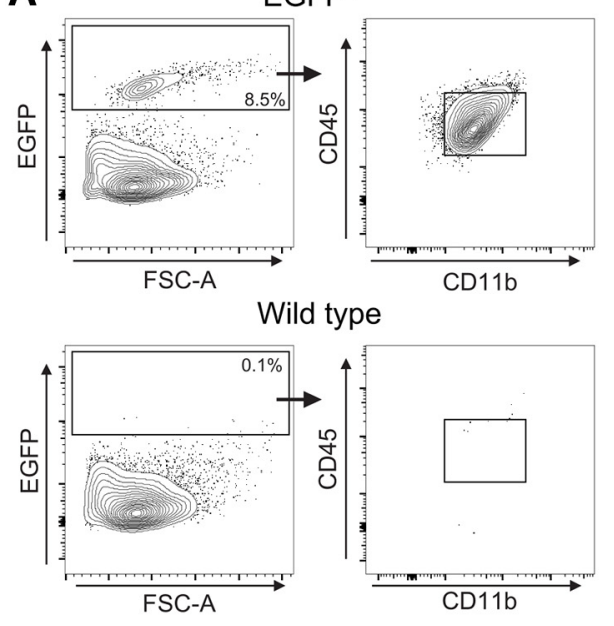

D
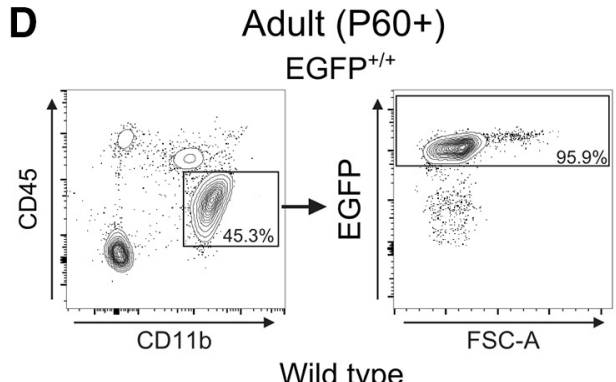

Wild type

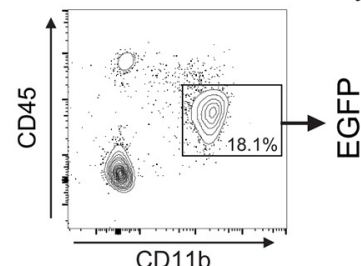

CD11b
B

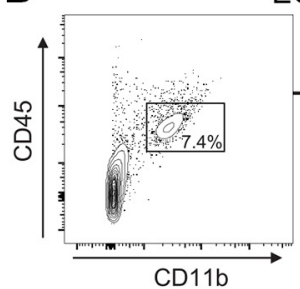

CD11b Wild type

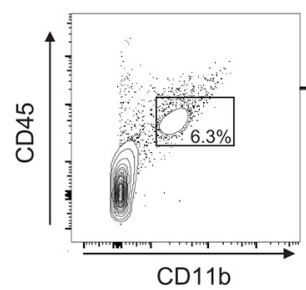

C

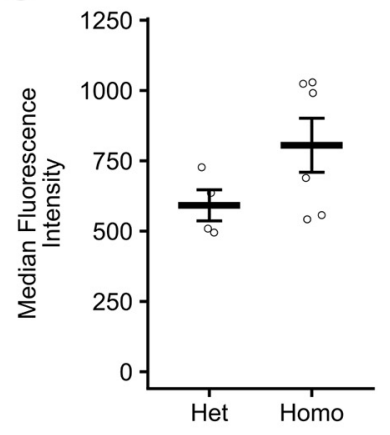

E

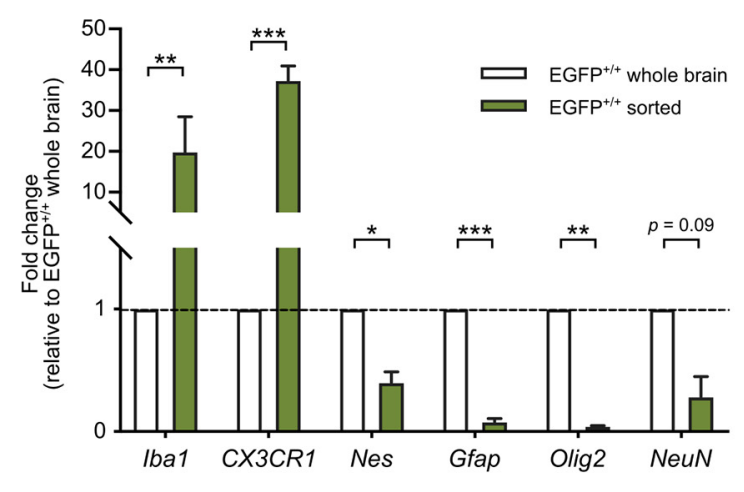

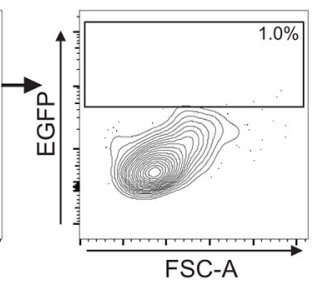

GFP $^{+/+}$

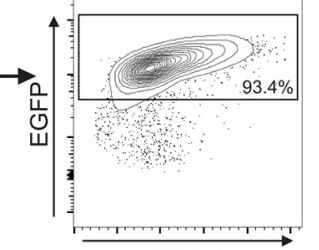

FSC-A

FSC-A

Figure 2. Flow cytometry validation of microglial Iba1-EGFP expression in neonates and adults. $\boldsymbol{A}$, Brain cells isolated from either $\mathrm{EGFP}^{+/+}$(top) or wild-type littermates (bottom) at P7 were gated as EGFP ${ }^{+}$and analyzed for their expression as CD11b ${ }^{+} / \mathrm{CD} 45^{\text {int }}$ (right). Gated on forward scatter (FSC)/side scatter (SSC), singlets, live, CD45 ${ }^{\text {int }}$, CD $11 b^{+}$. $\boldsymbol{B}$, The same samples from $\boldsymbol{A}$ were reanalyzed, gated as CD11b ${ }^{+} / C D 45^{\text {int }}$ (left) and analyzed for their expression as EGFP ${ }^{+}$(right). In $\boldsymbol{B}$ and $\boldsymbol{C}$, the black boxes indicate gates, and the percentage of cells within each gate are shown. $\boldsymbol{C}$, Quantification of the median fluorescence intensity of EGFP ${ }^{+}$cells isolated from heterozygous or homozygous littermates at P7. $\boldsymbol{D}$. Brain cells isolated from either EGFP ${ }^{+/+}$(top) or wild-type littermates (bottom) at P60 or later were gated as CD11b ${ }^{+} / \mathrm{CD} 45^{\text {int }}$ (left) and analyzed for their expression as EGFP ${ }^{+}$(right). E, qPCR quantification of microglial genes (Iba1, CX3CR1) and nonmicroglial genes (Nes, Gfap, Olig2, NeuN) from EGFP ${ }^{+}$sorted cells or whole-brain homogenates from EGFP ${ }^{+/+}$animals at P7. E, Brain cells from adult EGFP ${ }^{+/+}$and WT animals gated on CD $11 b^{+} / C D 45^{\text {int }}$ were analyzed for their expression as EGFP ${ }^{+}$. Histogram reflects a shift in EGFP fluorescence intensity in adult microglia-like cells in the Iba1-EGFP rat (green) compared with WT control (gray). Contour lines in $\boldsymbol{A}, \boldsymbol{B}$, and $\boldsymbol{D}$ represent $95 \%$ of the data at $5 \%$ intervals. Black boxes in $\boldsymbol{A}, \boldsymbol{B}$, and $\boldsymbol{D}$ indicate gates, and the percentage of cells within each gate are shown. Bars in $\boldsymbol{C}$ represent the mean \pm SEM. Bars in $\boldsymbol{E}$ represent the mean \pm SD. Open circles in $\boldsymbol{C}$ represent individual animal datapoints. ${ }^{\star} p<0.05 ;{ }^{* \star} p<0.01 ;{ }^{* \star} p<0.001$.

were not significantly different between the two genotypes $\left(p=0.1^{\text {d; }}\right.$ Fig. $\left.2 C\right)$. In adult rats $(>P 60), 94.8 \%$ of

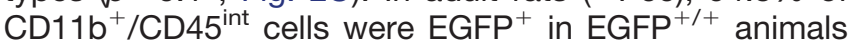
compared with $0.97 \%$ in age-matched wild types, consistent with our findings in neonates and demonstrating that transgene expression is robust and maintained into early adulthood (Fig. 2D, Table 3). Together, these data demonstrate that nearly all of the EGFP ${ }^{+}$cells in the brain express microglial markers, and of all the possible microglial cells, the vast majority are EGFP ${ }^{+}$in both neonates and adults.

To further verify the identity of $\mathrm{EGFP}^{+}$cells as microglia, we isolated EGFP ${ }^{+}$cells from EGFP ${ }^{+/+}$animals by FACS and used PCR to compare the relative expression of microglia-enriched genes (Iba1, CX3CR1) and nonmicroglial genes (Nes, Gfap, Olig2, NeuN) between EGFP ${ }^{+}$sorted cells and whole-brain homogenates from EGFP ${ }^{+/+}$littermates. Both Iba1 $\left(p=0.008^{\mathrm{e}}\right)$ and CX3CR1 $\left(p<0.001^{\mathrm{f}}\right)$ 

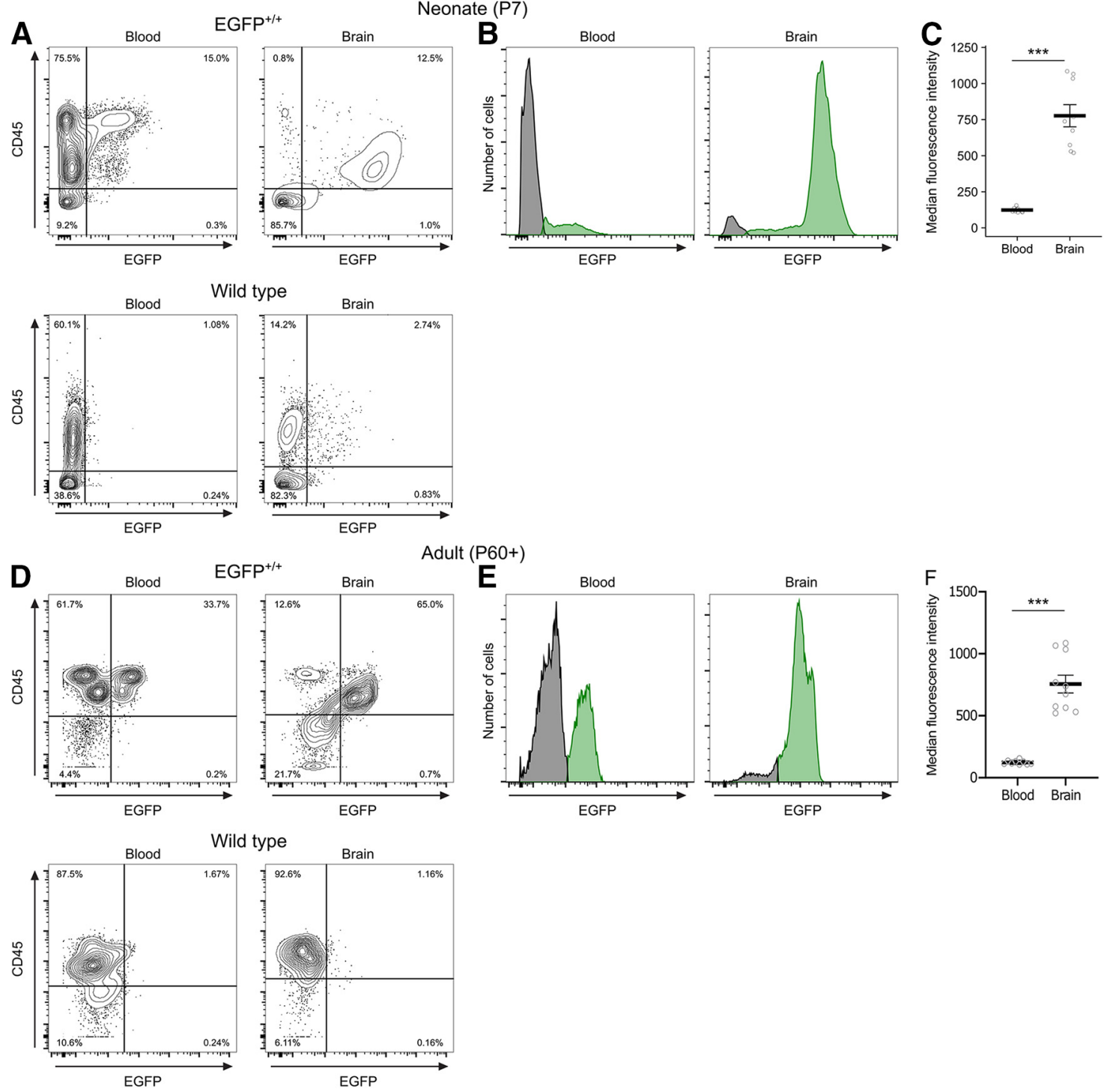

Figure 3. Comparison of EGFP signal in blood and brain. $\boldsymbol{A}$, Representative contour plots showing the gating strategy for median fluorescence intensity analysis in $\boldsymbol{B}$ and $\boldsymbol{C}$. Cells were gated as EGFP ${ }^{+}$and $\mathrm{CD} 5^{+}$in samples from blood (left) or brain (right) at P7 from either EGFP ${ }^{+/+}$(top) or wild-type littermates (bottom). $\boldsymbol{B}$, Representative histograms showing the distribution of EGFP fluorescence intensity of all $\mathrm{CD}_{4} 5^{+}$cells at P7 in the EGFP ${ }^{+/+}$rat (green) compared with wild-type controls (gray) in the blood and brain. $\boldsymbol{C}$, Quantification of median fluorescence intensity at P7. D, Representative contour plots showing the gating strategy for median fluorescence intensity analysis in $\boldsymbol{E}$ and $\boldsymbol{F}$. Cells were gated as EGFP ${ }^{+}$and CD45 ${ }^{+}$in samples from blood (left) or brain (right) in adults $>$ P60 from either EGFP ${ }^{+/+}$(top) or wild-type littermates (bottom). $\boldsymbol{E}$, Representative histogram showing the distribution of EGFP ${ }^{+}$ fluorescence intensity of all CD45 $5^{+}$cells in the adult EGFP ${ }^{+/+}$rat (green) compared with wild-type controls (gray) in the blood and brain. $\boldsymbol{F}$, Quantification of median fluorescence intensity in adults at P60 or later. Contour lines in $\boldsymbol{A}$ represent $95 \%$ of the data at $5 \%$ intervals. Bars in $\boldsymbol{C}$ and $\boldsymbol{F}$ represent the mean \pm SEM. Open circles represent individual animal datapoints.

were greatly enriched in the EGFP ${ }^{+}$sorted cell population, while markers for progenitors (Nes; $p=0.02^{9}$ ), astrocytes (Gfap; $p<0.001^{\mathrm{h}}$ ), oligodendrocytes (Olig2; $\left.p=0.007^{\mathrm{i}}\right)$, and neurons (NeuN; $p=0.09$ ) had far lower expression in EGFP $^{+}$sorted cells compared with unsorted whole-brain homogenates (Fig. 2E). These data confirm EGFP expression is highly specific to microglia in the brain.

As both microglia and peripheral myeloid cells express Iba1, we compared EGFP expression in blood and brain samples from $\mathrm{EGFP}^{+/+}$and wild-type neonates and adults using flow cytometry. We gated based on CD45 and EGFP expression and detected a distinct $\mathrm{EGFP}^{+}$population in the blood of $\mathrm{EGFP}^{+/+}$animals in both ages (Fig. $3 A, D$ ). EGFP ${ }^{+}$cells in the blood were mostly CD45 high, whereas in the brain, EGFP ${ }^{+}$ cells were CD45 ${ }^{\text {int}}$; and directly comparing the fluorescence intensity between the two populations found that brain $\mathrm{EGFP}^{+}$cells had a significantly greater MFI than EGFP ${ }^{+}$cells in the blood at both ages [neonates, $p<0.001^{\mathrm{k}}$ (Fig. 3B,C); adults, $p<0.001^{\prime}$ (Fig. 3E,F)].

Next, we examined EGFP expression in the spinal cord and dorsal root ganglion to determine the extent of EGFP 
A
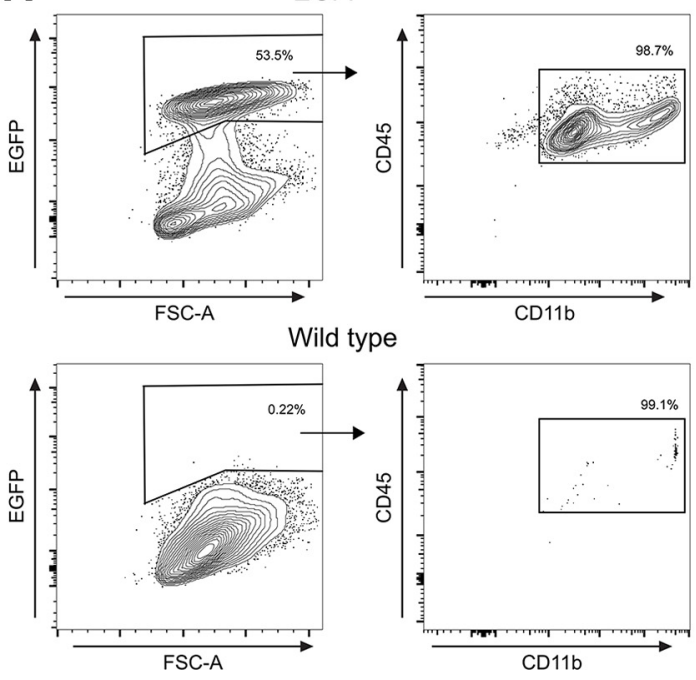

Spinal Cord

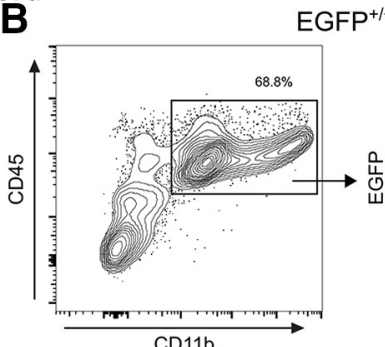

EGFP ${ }^{+/ 4}$

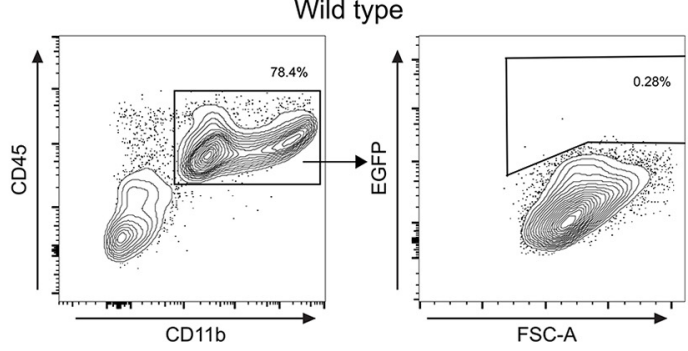

C
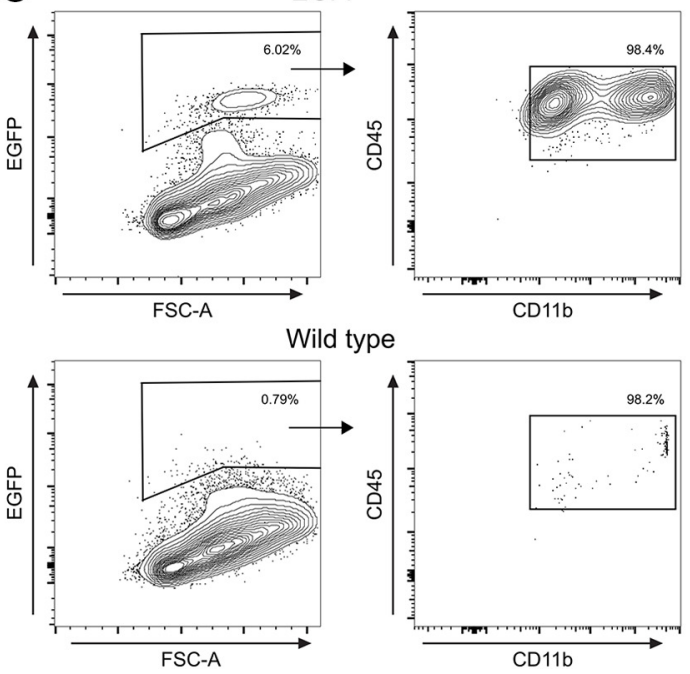

Dorsal Root Ganglion
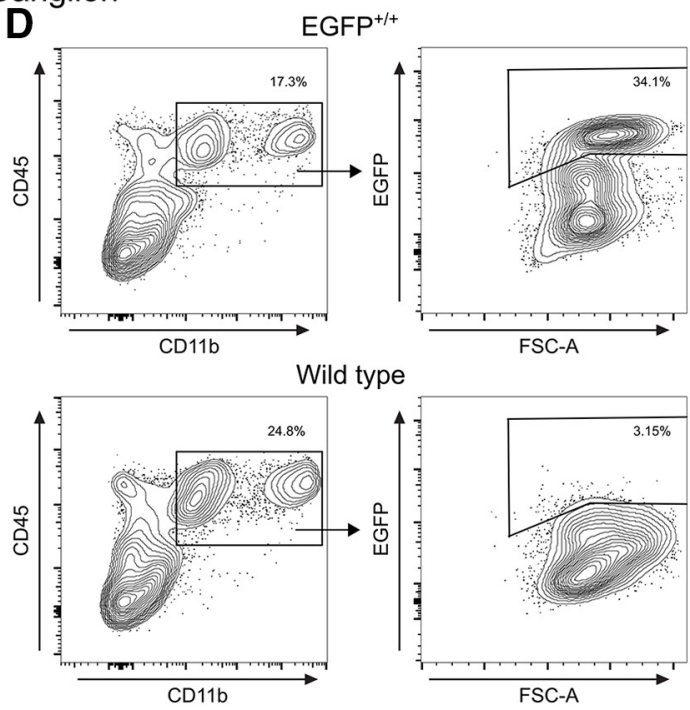

Figure 4. Comparison of EGFP signal in spinal cord and dorsal root ganglion. $\boldsymbol{A}$, Spinal cord cells isolated from either EGFP ${ }^{+/+}$(top) or

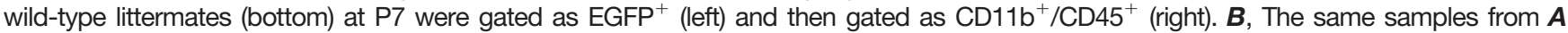
were reanalyzed, gated as $\mathrm{CD} 11 \mathrm{~b}^{+} / \mathrm{CD} 45^{+}$(left), then gated for EGFP expression (right). $\boldsymbol{C}$, Dorsal root ganglion cells isolated from either $\mathrm{EGFP}^{+/+}$(top) or wild-type littermates (bottom) at P7 were gated as EGFP ${ }^{+}$(left) and then gated as $\mathrm{CD}_{11 \mathrm{~b}}{ }^{+} / \mathrm{CD} 45^{+}$(right). $\boldsymbol{D}$, The same samples from $\boldsymbol{C}$ were reanalyzed, gated as $\mathrm{CD} 11 \mathrm{~b}^{+} / \mathrm{CD} 45^{+}$(left), then gated for EGFP expression (right). Contour lines in $\boldsymbol{A}-\boldsymbol{C}$ represent $95 \%$ of the data at $5 \%$ intervals. Black boxes in $\boldsymbol{A}-\boldsymbol{D}$ indicate gates, and the percentage of cells within each gate are shown.

expression in other neural tissues. We used flow cytometry to analyze the expression of CD45 and CD11b of acutely isolated cells from the spinal cord (Fig. $4 A, B$ ) and dorsal root ganglion (Fig. $4 C, D$ ) of $\mathrm{P} 7 \mathrm{EGFP}^{+/+}$or wildtype littermates. In the spinal cord, $\sim 59.8 \%$ of cells were $\mathrm{EGFP}^{+}$from $\mathrm{EGFP}^{+/+}$animals compared with $0.2 \%$ of cells from wild-type animals (Tables 2, 4). Of the EGFP ${ }^{+}$ cells, 99.2\% were identified as CD11b ${ }^{+} /$CD $45^{+}$(Fig. $4 A$, Table 3). In the dorsal root ganglion, $6.2 \%$ of cells were $\mathrm{EGFP}^{+}$in $\mathrm{EGFP}^{+/+}$animals (compared with $0.8 \%$ in wildtype animals), of which $97.6 \%$ were CD $11 b^{+} / \mathrm{CD} 45^{+}$(Fig. 4C, Table 4).
We again analyzed the data in reverse, first gating for

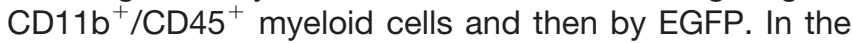
spinal cord, $73.9 \%$ of cells were CD11 $\mathrm{b}^{+} / \mathrm{CD}_{4} 5^{+}$and $80.0 \%$ of those cells were EGFP ${ }^{+}$(Fig. 4B, Table 4), while $18.3 \%$ of cells in the dorsal root ganglion were CD11 $\mathrm{b}^{+} /$ $\mathrm{CD}^{4} 5^{+}$with $32.4 \%$ of those cells being EGFP ${ }^{+}$(Fig. $4 D$, Table 4).

To further characterize the CD45 high hematopoietic cells (i.e., nonmicroglia cells) that express EGFP, we performed flow cytometry to analyze blood and brain samples from adults. In the brain, $52.2 \%$ of CD $45^{\text {high }}$ cells were EGFP ${ }^{+}$, while in the blood only $15.9 \%$ of CD $45^{\text {high }}$ 
Table 3: Iba1-EGFP Flow cytometry results

\begin{tabular}{|c|c|c|c|}
\hline & Wild type & $\mathrm{EGFP}^{+/+}$ & $\begin{array}{l}\text { Figure } \\
\text { reference }\end{array}$ \\
\hline$\overline{\mathrm{PN} 7}$ & $(n=4)$ & $(n=6)$ & \\
\hline $\mathrm{EGFP}^{+}$cells (mean counts $\pm \mathrm{SD}, \%$ live singlets) & $38 \pm 1,0.1 \pm 0.0 \%$ & $6039 \pm 440,9.8 \pm 0.7 \%$ & Figure $2 A$ \\
\hline 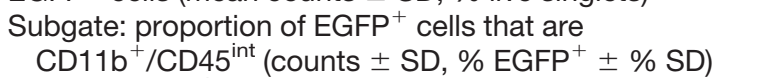 & N/A & $5754 \pm 402,95.3 \pm 6.7 \%$ & \\
\hline $\mathrm{CD} 11 \mathrm{~b}^{+} / \mathrm{CD} 45^{\text {int }}$ cells (counts/live singlets, $\%$ live singlets) & $5111 \pm 174,8.3 \pm 0.3 \%$ & $6054 \pm 324,9.8 \pm 0.5 \%$ & Figure $2 B$ \\
\hline $\begin{array}{l}\text { Subgate: proportion of CD } 11 \mathrm{~b}^{+} / \mathrm{CD} 45^{\text {int }} \text { cells } \\
\text { that are } \mathrm{EGFP}^{+} \text {(counts } \pm \mathrm{SD}, \% \mathrm{CD} 11 \mathrm{~b}^{+} / \\
\left.\mathrm{CD} 45^{\text {int }} \pm \% \mathrm{SD}\right)\end{array}$ & $33 \pm 2,0.7 \pm 0.0 \%$ & $5745 \pm 402,94.9 \pm 6.6 \%$ & \\
\hline Adult & $(n=2)$ & $(n=3)$ & \\
\hline $\mathrm{EGFP}^{+}$cells (mean counts $\pm \mathrm{SD}, \%$ live singlets) & $594 \pm 291,0.55 \pm 0.35 \%$ & $25,270 \pm 11,127,37.6 \pm 23.6 \%$ & $\mathrm{~N} / \mathrm{A}$ \\
\hline 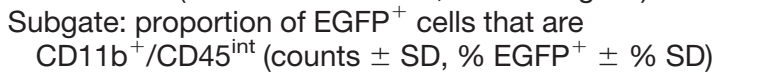 & $\mathrm{N} / \mathrm{A}$ & $22,766 \pm 10,203,89.8 \pm 1.46 \%$ & \\
\hline $\begin{array}{l}\mathrm{CD} 11 \mathrm{~b}^{+} / \mathrm{CD} 45^{\mathrm{int}} \text { cells (counts/live singlets, } \% \\
\text { live singlets) }\end{array}$ & $21,995 \pm 5699,19.3 \pm 1.73 \%$ & $23,892 \pm 10,768,36 \pm 22 \%$ & Figure $2 D$ \\
\hline $\begin{array}{l}\text { Subgate: proportion of CD } 11 b^{+} / C D 45^{\text {int }} \text { cells that } \\
\text { are EGFP }{ }^{+} \text {(counts } \pm \text { SD, } \% \text { CD } 11 b^{+} / C D 45^{\text {int }} \pm \% \text { SD) }\end{array}$ & $210 \pm 28,0.97 \pm 0.1 \%$ & $22,624 \pm 10,085,94.8 \pm 1.4 \%$ & \\
\hline
\end{tabular}

cells were $\mathrm{EGFP}^{+}\left(p=0.0072^{\mathrm{m}}\right.$; Fig. $\left.5 A\right)$. Other than microglia, myeloid cells/macrophages (CD45 high $/ C D 11 b^{+} /$ $\mathrm{RT}_{1 \mathrm{~B}}{ }^{+}$) were the most prevalent EGFP-expressing cell type in the brain, comprising $61.7 \%$ of EGFP ${ }^{+}$cells compared with $2.9 \%$ in the blood $\left(p<0.001^{\text {p }}\right.$; Fig. $\left.5 B, C\right)$ and were consistent with known lba1 expression in myeloid cells (Imai and Kohsaka, 2002; Ji et al., 2007; Jeong et al., 2013). Moreover, $85.4 \%$ of all myeloid cells/macrophages were $\mathrm{EGFP}^{+}$in the brain, while $62.2 \%$ were EGFP ${ }^{+}$in the

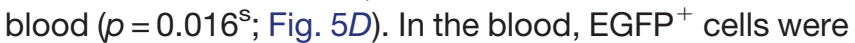
mostly monocytes (CD45 $5^{\text {high }} / \mathrm{CD} 11 \mathrm{~b}^{+} / \mathrm{His} 48^{+} ; 52.0 \%$ ) and were much less prevalent in the brain $(19.0 \%$, $p=0.025^{q}$; Fig. $\left.5 B, C\right)$; of the total monocyte population, $40 \%$ were $\mathrm{EGFP}^{+}$in the blood and $69.4 \%$ were $\mathrm{EGFP}^{+}$in the brain $\left(p=0.062^{\mathrm{t}}\right.$; Fig. $\left.5 E\right)$. Both T cells $(0.1 \%$ in blood

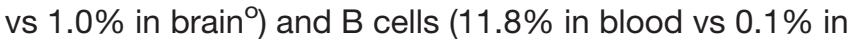
brain $^{n}$ ) were far less frequent in the EGFP ${ }^{+}$population of both tissue types. Finally, our antibody panel failed to label a population of EGFP" ${ }^{+}$cells (termed "other"; Fig. 5B,C) that represented $28.1 \%$ of cells in the blood and $15.0 \%$ in the brain $^{r}$. Given the design of our antibody panel, these cells are most likely nonclassical monocytes as His48 mostly labels classical monocytes and neutrophils, and that would explain the increased prevalence of this population in the blood compared with the brain (Barnett-Vanes et al., 2016).

\section{Histologic validation of EGFP ${ }^{+}$cells}

To determine whether EGFP expression could be reliably detected in all microglia throughout the brain, we used histology to assess the colocalization of Iba1 and GFP by immunolabeling for both proteins. We quantified microglia in several regions on $\mathrm{P} 7$, as follows: the prefrontal cortex (PFC; Fig. 6A-C), nucleus accumbens (NAc; Fig. 6D-F), hippocampus (Hipp; Fig. 6G-I), and amygdala (Amyg; Fig. $6 J-L$ ). We found that across all regions, $>90 \%$ of all $\mathrm{Iba}^{+}{ }^{+}$cells colabeled as $\mathrm{GFP}^{+}$in $\mathrm{EGFP}^{+/-}$ animals $\left(93.97 \%\right.$ in $\mathrm{PFC}^{\mathrm{u}}, 91.59 \%$ in $\mathrm{NAc}^{\mathrm{v}}, 92.59 \%$ in $\mathrm{Hipp}^{\mathrm{w}}, 91.39 \%$ in $\left.\mathrm{Amyg}^{\mathrm{x}}\right)$ and $\sim 98 \%$ of $\mathrm{Iba1}^{+}$cells were GFP $^{+}$in $\mathrm{EGFP}^{+/+}$animals $\left(100 \%\right.$ in $\mathrm{PFC}^{\mathrm{u}}$; $98.96 \%$ in $\mathrm{NAc}^{\mathrm{v}}$; $95.34 \%$ in $\mathrm{Hipp}^{\mathrm{w}}$; $100 \%$ in $\mathrm{Amyg}^{\mathrm{x}}$ ).

\section{Ex vivo and in vivo imaging of EGFP ${ }^{+}$cells}

One of the most significant advantages of microglia reporter mice has been the ability to monitor microglia dynamics in real time. To determine whether the lba1-EGFP rat was suitable for live imaging studies, we first used

Table 4: Iba1-EGFP Spinal cord and dorsal root ganglion flow cytometry results

\begin{tabular}{|c|c|c|c|}
\hline & Wild type & $\mathrm{EGFP}^{+/+}$ & Figure reference \\
\hline PN7 spinal cord & $(n=1)$ & $(n=2)$ & \\
\hline EGFP $^{+}$cells (mean counts \pm SD, \% live singlets) & $112,0.2 \%$ & $35,385 \pm 3896,59.8 \pm 8.8 \%$ & Figure $4 A$ \\
\hline 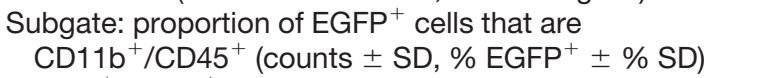 & $\mathrm{N} / \mathrm{A}$ & $35,105 \pm 4094,99.15 \pm 0.6 \%$ & \\
\hline $\mathrm{CD} 1 \mathrm{~b}^{+} / \mathrm{CD} 5^{+}$cells (counts/live singlets, $\%$ live singlets) & $40163,78.4 \%$ & $43,770 \pm 2592,73.9 \pm 7.1 \%$ & Figure $4 B$ \\
\hline $\begin{array}{l}\text { Subgate: proportion of CD } 11 b^{+} / \mathrm{CD}_{4} 5^{+} \text {cells that } \\
\left.\text { are EGFP }{ }^{+} \text {(counts } \pm \mathrm{SD}, \% \mathrm{CD} 11 \mathrm{~b}^{+} / \mathrm{CD} 45^{+} \pm \% \mathrm{SD}\right)\end{array}$ & $111,0.3 \%$ & $35,755 \pm 4207,80 \pm 4.6 \%$ & \\
\hline PN7 dorsal root ganglion & $(n=1)$ & $(n=3)$ & \\
\hline $\mathrm{EGFP}^{+}$cells (mean counts $\pm \mathrm{SD}, \%$ live singlets) & $170,0.8 \%$ & $2350 \pm 240,6.18 \pm 2.0 \%$ & Figure $4 C$ \\
\hline 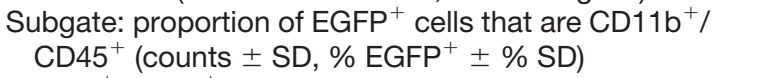 & $\mathrm{N} / \mathrm{A}$ & $2292 \pm 224,97.6 \pm 0.7 \%$ & \\
\hline $\mathrm{CD} 11 \mathrm{~b}^{+} / \mathrm{CD} 45^{+}$cells (counts/live singlets, $\%$ live singlets) & $5308,24.8 \%$ & $7162 \pm 993,18.3 \pm 2.7 \%$ & Figure $4 D$ \\
\hline $\begin{array}{l}\text { Subgate: proportion of CD } 11 b^{+} / \mathrm{CD}_{4} 5^{+} \text {cells that are } \\
\text { EGFP }^{+} \text {(counts } \pm \mathrm{SD}, \% \mathrm{CD} 11 \mathrm{~b}^{+} / \mathrm{CD} 45^{+} \pm \% \text { SD) }\end{array}$ & $167,3.2 \%$ & $2289 \pm 226,32.4 \pm 6.1 \%$ & \\
\hline
\end{tabular}



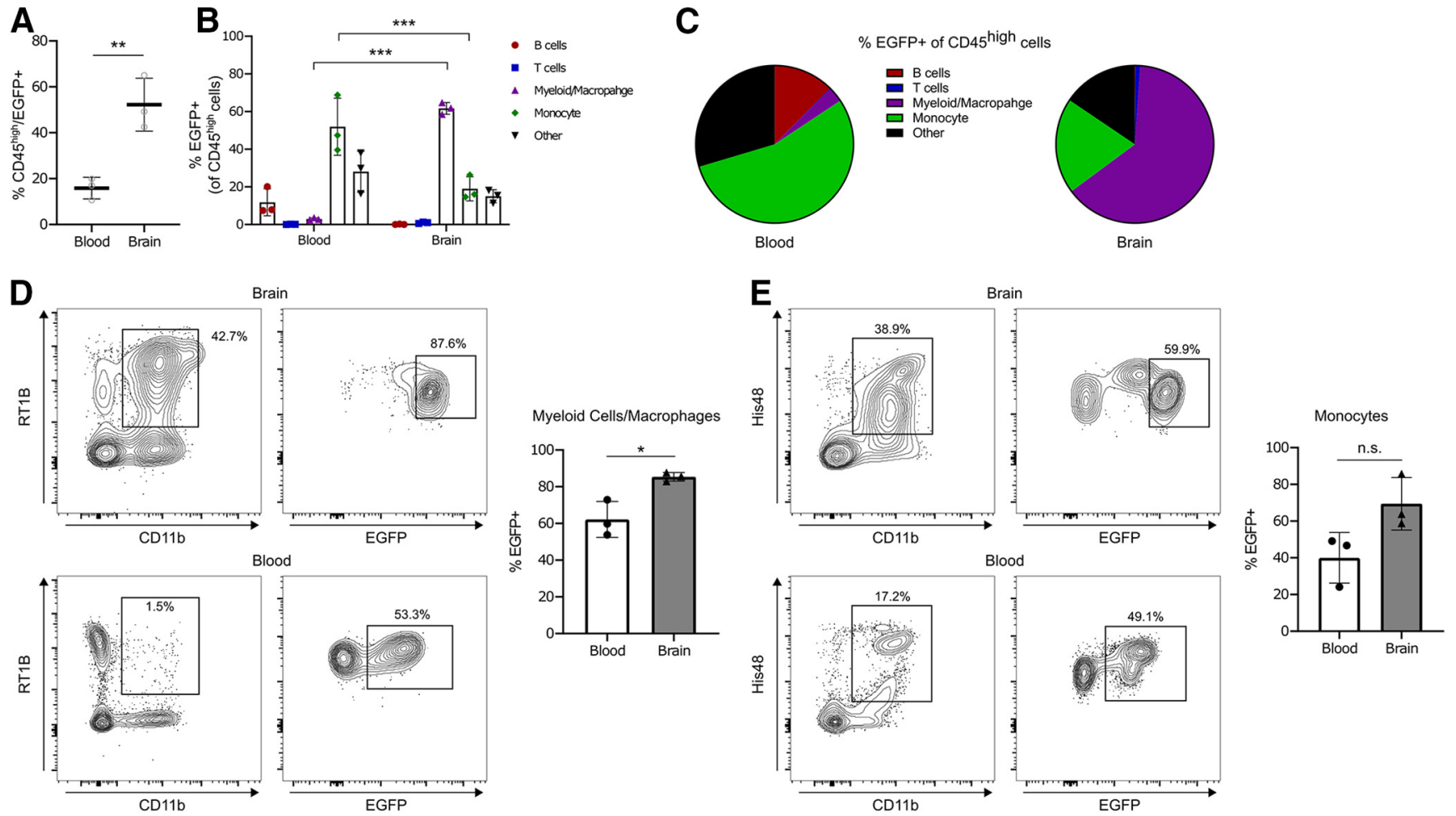

Figure 5. Flow cytometric characterization of EGFP ${ }^{+}$peripheral cells in the adult. $\boldsymbol{A}$, Quantification of the percentage of CD45 high peripheral immune cells expressing EGFP in the brain compared with the blood. $\boldsymbol{B}$, Graph depicting the population subsets of

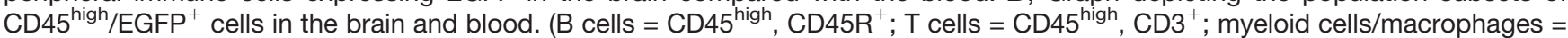
$\mathrm{CD} 45^{\text {high }}, \mathrm{CD}_{11 \mathrm{~b}^{+}}, \mathrm{RT}_{1 \mathrm{~B}}{ }^{+} ;$monocytes $=\mathrm{CD} 45^{\text {high }}, \mathrm{CD}_{11 \mathrm{~b}^{+}}$, His48 ${ }^{+}$; other $=\mathrm{CD} 45^{\text {high }}$, additional immune cells not determined by this panel). $\boldsymbol{C}$, Pie charts showing the relative distribution of CD45 high/EGFP ${ }^{+}$immune cells in the blood (left) and brain (right). $\boldsymbol{D}$, Contour plots depicting the gating strategy for myeloid cells/macrophages in the brain (top) and blood (bottom). Quantification of the percentage of myeloid cells/macrophages expressing EGFP in the blood and brain. $\boldsymbol{E}$, Contour plots showing the gating strategy for monocytes in the brain (top) and blood (bottom). Quantification of the percentage of monocytes expressing EGFP in the blood and brain. Contour lines $(\boldsymbol{D}, \boldsymbol{E})$ represent $95 \%$ of the data at $5 \%$ intervals. Bars represent the mean \pm SD. Open circles and solid shapes represent individual animal datapoints. ${ }^{\star} p<0.05$; ${ }^{\star \star} p<0.01$; ${ }^{\star \star *} p<0.001$.

confocal microscopy to image EGFP ${ }^{+}$cells in acute brain slices from P7 EGFP ${ }^{+/+}$animals. We imaged for 4 min to measure microglia dynamics under baseline conditions, then applied $1 \mathrm{~mm}$ ATP to the bath solution for the remainder of the 20 min assay. The EGFP signal was sufficient to image multiple cells across a large field of view and track microglial process dynamics over time (Fig. 7A,B, Movie 1). Moreover, we were able to identify filopodia formation in response to ATP application (Fig. 7C) and quantify measures of microglia movement such as $x-y$ displacement (Fig. 7D), process retraction/extension (Fig. 7E), and process velocity (Fig. 7F).

To determine whether this model is equally suitable for in vivo studies, we used multiphoton imaging to visualize microglia dynamics through a thinned skull preparation in $\mathrm{P} 14$ Iba1-EGFP ${ }^{+/+}$rats. In parallel and as a positive control, we used the same procedure to image adult CX3CR1-EGFP ${ }^{+/-}$mice, which are widely used to study microglia in vivo (Jung et al., 2000; Guttenplan and Liddelow, 2019; Moseman et al., 2020). Though CX3CR1$E G F P^{+/-}$microglia exhibited brighter fluorescence, Iba1$E G F P^{+/+}$microglia were dynamic from frame to frame (Fig. $7 H$ ), matching the activity observed in the CX3CR1EGFP mice.

\section{Discussion}

Described here is a novel transgenic rat, $S D-T g$ (lba1EGFP)Mmmc, that leverages EGFP expression under the control of the Iba1 promoter. Utilization of a $2 \mathrm{~A}$ self-splicing peptide as a linker between the EGFP and Iba1 coding sequence expressed in series from the same gene locus enables the expression of EGFP with the same specificity, timing, and abundance of endogenous lba1. Cleavage at the P2A peptide in particular has been shown to be highly efficient, both in vitro and in vivo, and in mice $<10 \%$ of translational products are uncleaved fusion protein (Kim et al., 2011; Liu et al., 2017). Our SD-Tg(Iba1-EGFP) $M m m c$ rats show the same high-efficiency splicing, as we were unable to detect any EGFP-P2A-Iba1 fusion protein using Western blotting. This system also preserves endogenous levels of Iba1 protein in our transgenic rats. Using a combination of flow cytometry, PCR, and immunohistochemistry, we show that EGFP expression faithfully identifies microglia in the brain. We further demonstrate the utility of this model in expanding the repertoire of microglia techniques in the rat, by live imaging microglia process motility in acute slice and in vivo preparations.

Iba1 protein, while traditionally held as the "gold standard" for identifying microglia in the brain, is also 
A
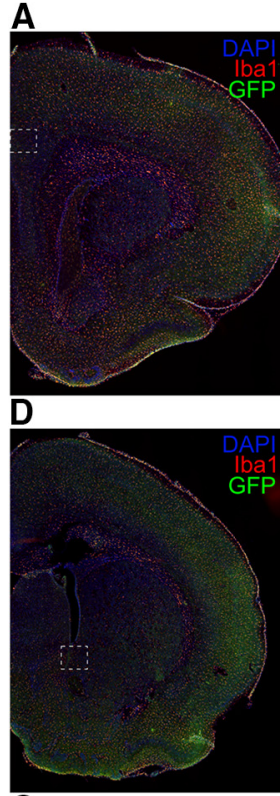

G

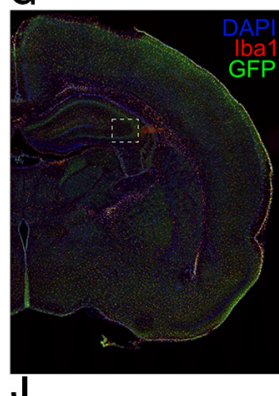

J

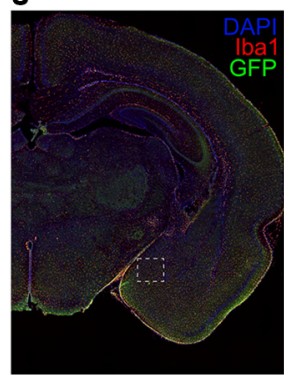

B

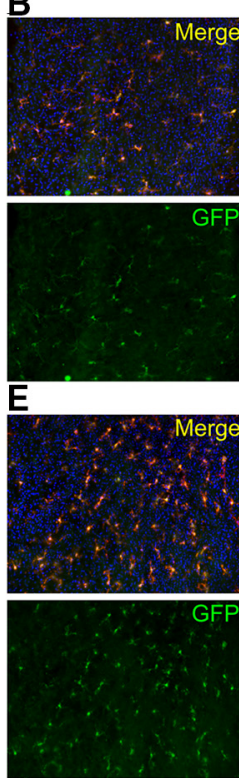

$\mathrm{H}$
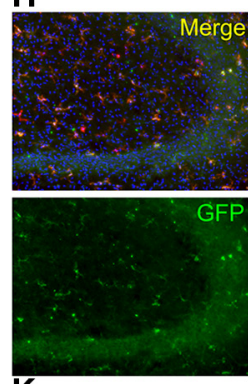

K

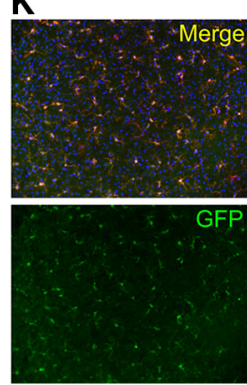

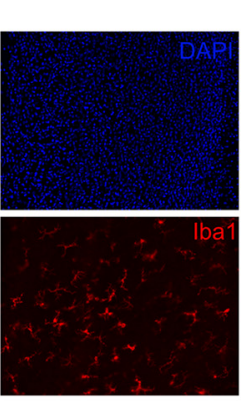

C

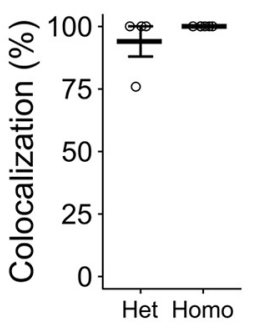

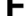
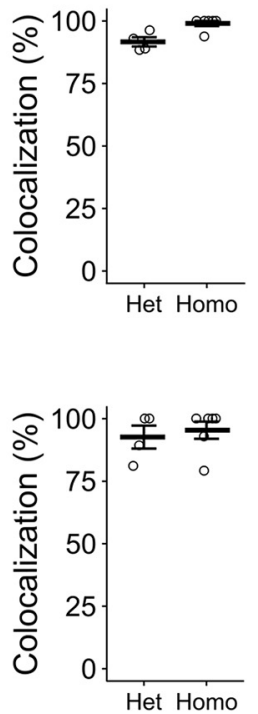

政
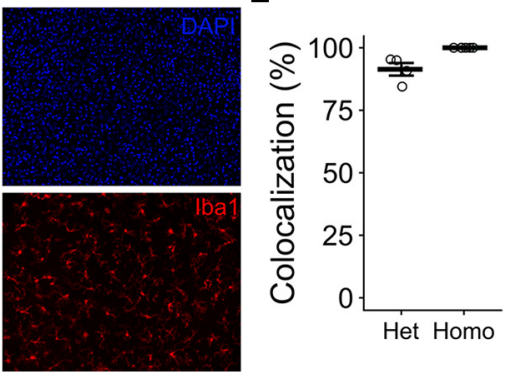

Figure 6. Histologic validation of knock-in efficiency. $\boldsymbol{A}, \boldsymbol{D}, \boldsymbol{G}, \boldsymbol{J}$, Representative coronal images from EGFP ${ }^{+/-}$animals antibody labeled for lba1 (red), GFP (green), and colabeled with DAPI (blue). White box shows the region analyzed for the prefrontal cortex (A$\boldsymbol{C})$, nucleus accumbens $(\boldsymbol{D}-\boldsymbol{F})$, hippocampus $(\boldsymbol{G}-\boldsymbol{I})$, and amygdala $(\boldsymbol{J}-\boldsymbol{L})$. $\boldsymbol{B}, \boldsymbol{E}, \boldsymbol{H}, \boldsymbol{K}$, Representative single-channel and merged images at $20 \times$ magnification. $\boldsymbol{C}, \boldsymbol{F}, \boldsymbol{I}, \boldsymbol{L}$, Quantification of the percentage of colocalization between GFP and Iba1 in heterozygous and homozygous animals. Bars represent the mean \pm SEM. Open circles represent individual animal datapoints.

expressed by a variety of monocytes/macrophages throughout the body and is robustly expressed in the spermatids of the testis (Köhler, 2007). While we did not perform a comprehensive analysis across tissue types, in the brains of our transgenic model EGFP expression was almost entirely limited to microglia as $>95 \%$ of EGFP ${ }^{+}$ cells colabeled as $\mathrm{CD} 11 \mathrm{~b}^{+} / \mathrm{CD} 45^{\text {int }}$ by flow cytometry and between $95 \%$ and $100 \%$ of EGFP ${ }^{+}$cells colabeled as Iba $1^{+}$by histology depending on genotype. Moreover, EGFP expression was robust in both neonates and adults, demonstrating that the transgene is expressed early and is stable into early adulthood. By using flow cytometry, we detected $\mathrm{EGFP}^{+}$cells in the blood and a small population of EGFP ${ }^{+}$nonmicroglial cells in the brain. $\mathrm{EGFP}^{+}$cells in the blood were largely monocytes, while nonmicroglial $\mathrm{EGFP}^{+}$cells in the brain were largely myeloid cells/macrophages. A significantly larger percentage of myeloid cells/macrophages expressed EGFP in the brain compared with the blood, which is consistent with an upregulation of Iba1 in myeloid cells on entering the brain and establishing tissue residence (Imai and Kohsaka, 2002; Kishimoto et al., 2019; Swanson et al., 2020). Moreover, the percentage of monocytes expressing EGFP was not different between the blood and brain, which is expected 
A

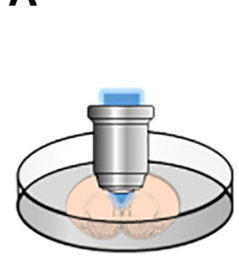

Acute slice imaging Iba1-EGFP ${ }^{+/ *}$
B

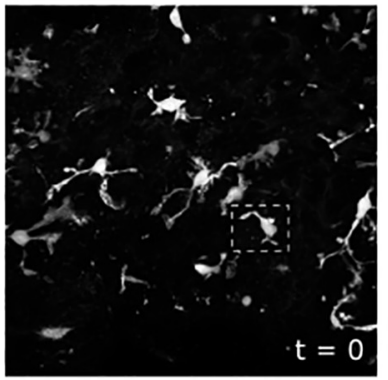

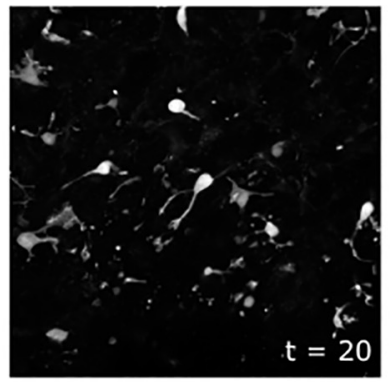

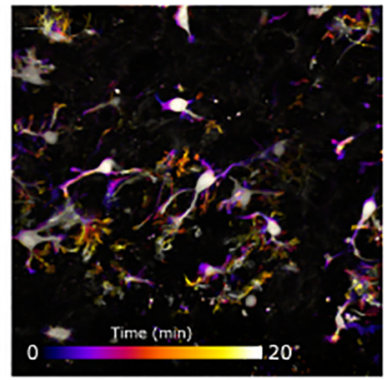

C
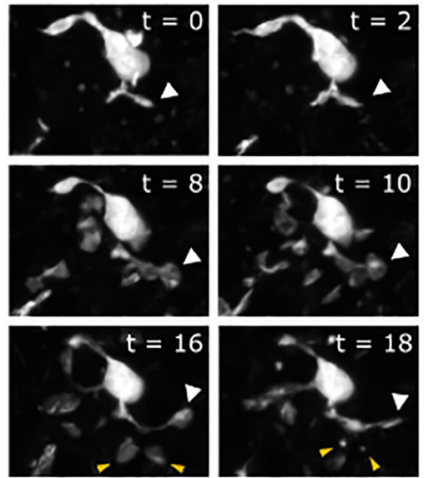

E

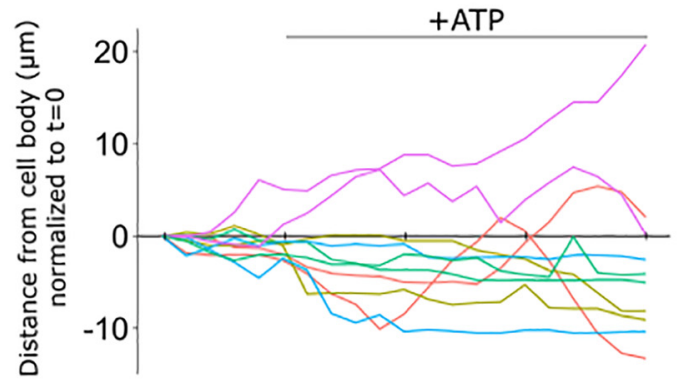

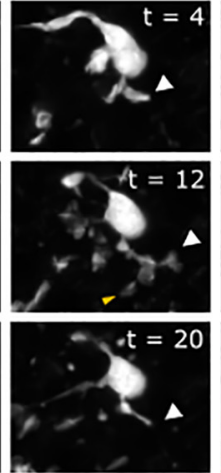

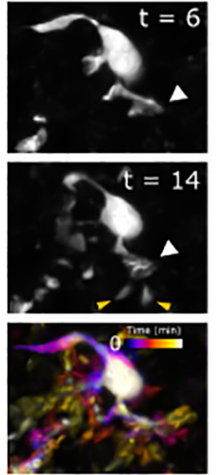

D

$\mathbf{F}$

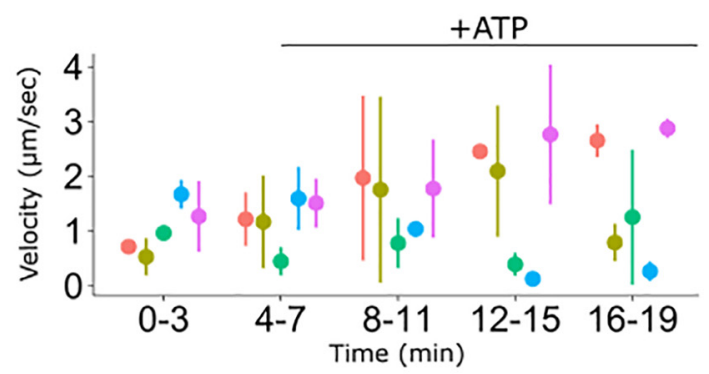

G

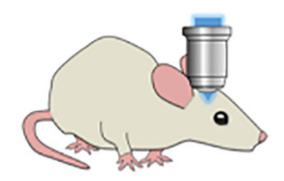

In vivo multi photon imaging CX3CR1-EGFP ${ }^{+/-}$ or Iba1-EGFP ${ }^{+/ *}$
H

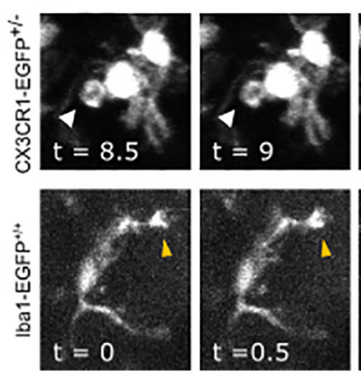

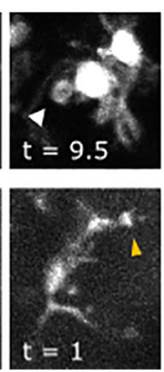

$X-Y$ process displacement

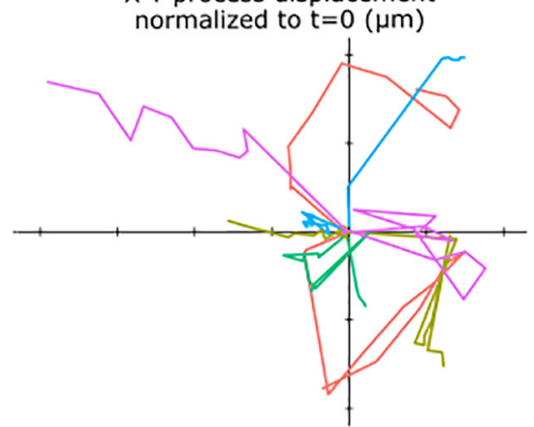

\section{(n)}

(n) 
continued

s intervals. White arrows track the internalization of a phagocytic cup and yellow arrows track the retraction of a microglial process. In $\boldsymbol{C}, \boldsymbol{D}$, and $\boldsymbol{E}$, each color represents a different cell; same color traces represent different processes from the same cell. In $\boldsymbol{D}$ and $\boldsymbol{E}$, black bar indicates the time and duration of ATP application. In $\boldsymbol{F}$, data are represented as the mean \pm range.

in a naive, nonactivated state where circulating monocytes are not actively recruited to the brain.

Outside of the brain, we were able to detect EGFP expression in other neural tissues, for example the spinal cord and dorsal root ganglion. The spinal cord was enriched with $\mathrm{EGFP}^{+}$cells, whereas the dorsal root ganglion had far fewer EGFP ${ }^{+}$cells, which is to be expected given the distributions of microglia and macrophages in CNS and peripheral nervous system tissue, respectively (Xuan et al., 2019; Kolter et al., 2020). In both tissues, the vast majority of $\mathrm{EGFP}^{+}$cells were CD $11 \mathrm{~b}^{+} / \mathrm{CD} 45^{+}$, further demonstrating that EGFP expression is highly specific to select immune cell populations.

The SD-Tg(Iba1-EGFP) rat that we describe here presents several significant advancements over traditional methods. First, endogenous fluorescent reporters greatly facilitate the analysis and purification of $\mathrm{Iba1}^{+}$ cells, without the need for multiple antibody-labeling steps or complicated antibody panels. By minimizing tissue processing, microglia can be quickly isolated from the brain and analyzed by flow cytometry or FACS, and from much smaller starting volumes or brain regions. The ability to use FACS to sort and then sequence single-cell RNA using microglia from genetically modified mice expressing EGFP has considerably expanded our understanding of these critical cells in the mature and developing brain and in response to disease or injury

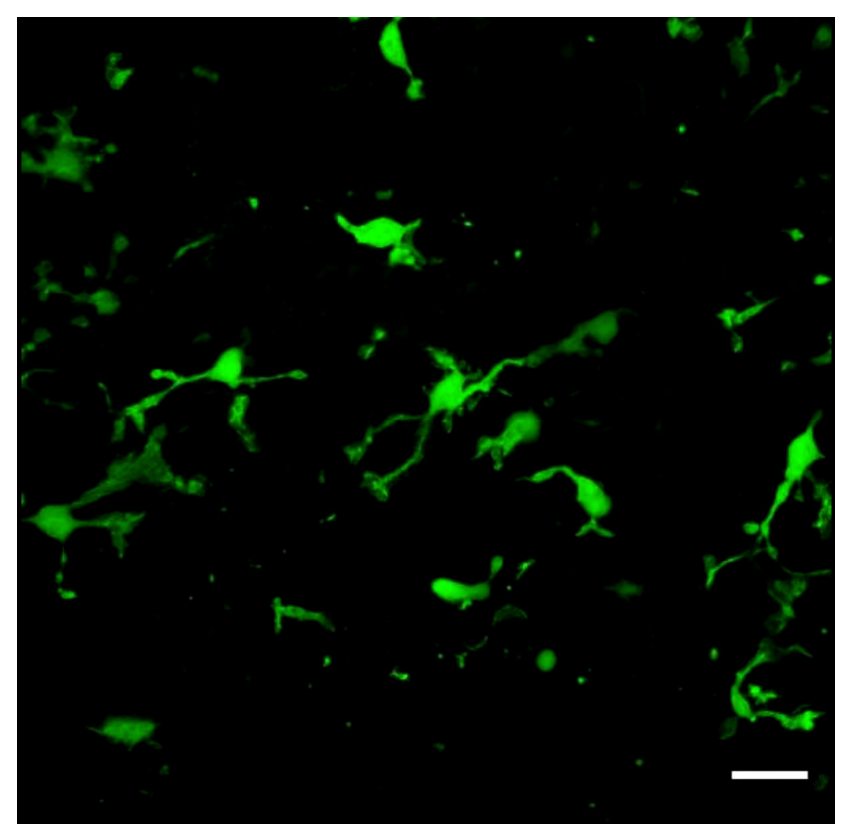

Movie 1. Time-lapse video of $\mathrm{EGFP}^{+}$microglia in acute slices. Representative field of view of microglia from an EGFP ${ }^{+/+}$animal. Confocal $z$-stacks were acquired in $1 \mathrm{~min}$ intervals. ATP (1 $\mathrm{mm}$ in aCSF) was bath applied after the fourth frame, as denoted by "+ATP" in the video. Scale bar, $20 \mu \mathrm{m}$. [View online]
(Hammond et al., 2019; Li et al., 2019). To date, this level of analysis has been out of reach for researchers using the rat model.

Second, endogenous reporters drastically improve the quality and capabilities of both live and ex vivo imaging studies. Compared with previous methodology, which largely relied on the application of fluorescent labels that bind to microglia membrane receptors (e.g., ib4 labeling), the GFP signal in this rat acts as a cell fill, which allows detailed imaging of microglia processes and dynamics over time. This can be exploited for multiple purposes, including imaging of microglia motility in acute slices, as was done here. There is also the potential for in vivo imaging for longitudinal studies of particular brain regions after stroke, traumatic brain injury (TBI), or other manipulations, as was done in the mouse (Pernici et al., 2019), and is now feasible in the rat, as demonstrated here. Given the importance of microglia function during early brain development (Frost and Schafer, 2016), the larger size of rats may allow for in vivo imaging during developmental ages that would not be feasible in mice. Last, the celebrated and impactful observations that microglia can engulf microstructures such as synapses and thereby prune them to sculpt neural circuit development, was achieved with the use of a mouse model in which microglia expressed GFP (Schafer and Stevens, 2013). This transformative finding can now be corroborated and expanded on in the rat model.

Third, given the fidelity of EGFP expression in blood monocytes and macrophages, this rat may be beneficial for studying immune responses in models of ischemic stroke, infection, or TBI where peripheral monocytes infiltrate the brain (Yang et al., 2019). lba1 is a marker of peripheral tissue-resident macrophages, so using this rat may be useful in studying an array of other myeloid celldriven responses throughout the body (Wijesundera et al., 2013; Suenaga et al., 2016; Ma et al., 2017). A further hidden benefit of this feature is the ability to screen animals for EGFP expression in the brain by first screening the blood. Although brain EGFP expression was higher than that in blood, the blood CD45 compartment still showed a one-log shift in EGFP expression, indicating a potential for flow cytometric analysis of the blood as a screening tool for transgene positivity. Our recommended panel for blood screening (Fig. $3 A, D$ ) would include only a CD45 antibody and require analysis of only two fluorescent channels, making this screening adaptable to most, if not all, flow cytometers. We found that at P7 and in adults, Iba1-EGFP $^{+}$cells are present in the blood and comparable to expression in the brain.

In summary, we report here the generation of a novel transgenic rat, SD-Tg(Iba1-EGFP)Mmmc, in which microglia and some peripheral immune cells express EGFP protein in sufficient quantity to allow for flow sorting and FACS, and in vivo and ex vivo visualization. The rat has 
long been a favored animal model in neuroscience, but the inability to readily genetically modify them has diminished use over the past 2 decades. With the advent of CRISPR technology, this is likely to change, and we offer this model as one such example of the changes to come.

\section{References}

Barnett-Vanes A, Sharrock A, Birrell MA, Rankin S (2016) A single 9colour flow cytometric method to characterise major leukocyte populations in the rat: validation in a model of LPS-induced pulmonary inflammation. PLoS One 11:e0142520.

Bilbo SD, Schwarz JM (2012) The immune system and developmental programming of brain and behavior. Front Neuroendocrinol 33:267-286.

Dailey ME, Eyo U, Fuller L, Hass J, Kurpius D (2013) Imaging microglia in brain slices and slice cultures. Cold Spring Harb Protoc 2013:1142-1148.

Davalos D, Grutzendler J, Yang G, Kim JV, Zuo Y, Jung S, Littman DR, Dustin ML, Gan WB (2005) ATP mediates rapid microglial response to local brain injury in vivo. Nat Neurosci 8:752-758.

Ellenbroek B, Youn J (2016) Rodent models in neuroscience research: is it a rat race? Dis Model Mech 9:1079-1087.

Frost JL, Schafer DP (2016) Microglia: architects of the developing nervous system. Trends Cell Biol 26:587-597.

Guttenplan KA, Liddelow SA (2019) Astrocytes and microglia: models and tools. J Exp Med 216:71-83.

Hagemeyer N, Hanft KM, Akriditou MA, Unger N, Park ES, Stanley ER, Staszewski O, Dimou L, Prinz M (2017) Microglia contribute to normal myelinogenesis and to oligodendrocyte progenitor maintenance during adulthood. Acta Neuropathol 134:441-458.

Hammond TR, Dufort C, Dissing-Olesen L, Giera S, Young A, Wysoker A, Walker AJ, Gergits F, Segel M, Nemesh J, Marsh SE, Saunders A, Macosko E, Ginhoux F, Chen J, Franklin RJM, Piao X, McCarroll SA, Stevens B (2019) Single-cell RNA sequencing of microglia throughout the mouse lifespan and in the injured brain reveals complex cell-state changes. Immunity 50:253-271.e6.

Hirasawa T, Ohsawa K, Imai Y, Ondo Y, Akazawa C, Uchino S, Kohsaka $S$ (2005) Visualization of microglia in living tissues using Iba1-EGFP transgenic mice. J Neurosci Res 81:357-362.

Huang J, Liu G, Shi B, Shi G, He X, Lu Z, Zheng J, Zhang H, Chen H, Zhu Z (2018) Inhibition of microglial activation by minocycline reduced preoligodendrocyte injury in a neonatal rat brain slice model. J Thorac Cardiovasc Surg 150:2271-2280.

Imai Y, Kohsaka S (2002) Intracellular signaling in M-CSF-induced microglia activation: role of Iba1. Glia 40:164-174.

Jaramillo S, Zador AM (2014) Mice and rats achieve similar levels of performance in an adaptive decision-making task. Front Syst Neurosci 8:173

Jeong HK, Ji K, Min K, Joe EH (2013) Brain inflammation and microglia: facts and misconceptions. Exp Neurobiol 22:59-67.

Ji KA, Yang MS, Jeong HK, Min KJ, Kang SH, Jou I, Joe EH (2007) Resident microglia die and infiltrated neutrophils and monocytes become major inflammatory cells in lipopolysaccharide-injected brain. Glia 55:1577-1588.

Jung S, Aliberti J, Graemmel P, Sunshine MJ, Kreutzberg GW, Sher A, Littman DR (2000) Analysis of fractalkine receptor CX(3)CR1 function by targeted deletion and green fluorescent protein reporter gene insertion. Mol Cell Biol 20:4106-4114.

Kaiser T, Feng G (2019) Tmem119-EGFP and Tmem119-CreERT2 transgenic mice for labeling and manipulating microglia. eNeuro 6: ENEURO.0448-18.2019.

Kim JH, Lee SR, Li LH, Park HJ, Park JH, Lee KY, Kim MK, Shin BA, Choi SY (2011) High cleavage efficiency of a 2A peptide derived from porcine teschovirus- 1 in human cell lines, zebrafish and mice. PLoS One 6:e18556.
Kishimoto I, Okano T, Nishimura K, Motohashi T, Omori K (2019) Early development of resident macrophages in the mouse cochlea depends on yolk sac hematopoiesis. Front Neurol 10:1115.

Köhler C (2007) Allograft inflammatory factor-1/lonized calciumbinding adapter molecule 1 is specifically expressed by most subpopulations of macrophages and spermatids in testis. Cell Tissue Res 330:291-302.

Kolter J, Kierdorf K, Henneke P (2020) Origin and differentiation of nerve-associated macrophages. J Immunol 204:271-279.

Lawson LJ, Perry VH, Dri P, Gordon S (1990) Heterogeneity in the distribution and morphology of microglia in the normal adult mouse brain. Neuroscience 39:151-170.

Lenz KM, Nelson LH (2018) Microglia and beyond: innate immune cells as regulators of brain development and behavioral function. Front Immunol 9:698.

Lenz KM, Nugent BM, Haliyur R, McCarthy MM (2013) Microglia are essential to masculinization of brain and behavior. J Neurosci 33:2761-2772.

Li Q, Cheng Z, Zhou L, Darmanis S, Neff NF, Okamoto J, Gulati G, Bennett ML, Sun LO, Clarke LE, Marschallinger J, Yu G, Quake SR, Wyss-Coray T, Barres BA (2019) Developmental heterogeneity of microglia and brain myeloid cells revealed by deep single-cell RNA sequencing. Neuron 101:207-223.e10.

Liu Z, Chen O, Wall BJ, Zheng M, Zhou Y, Wang L, Vaseghi HR, Qian L, Liu J (2017) Systematic comparison of 2A peptides for cloning multi-genes in a polycistronic vector. Sci Rep 7:2193.

Ma W, Zhang Y, Gao C, Fariss RN, Tam J, Wong WT (2017) Monocyte infiltration and proliferation reestablish myeloid cell homeostasis in the mouse retina following retinal pigment epithelial cell injury. Sci Rep 7:8433.

Meijering E, Dzyubachyk O, Smal I (2012) Methods for cell and particle tracking. Methods Enzymol 504:183-200.

Moseman EA, Blanchard AC, Nayak D, McGavern DB (2020) T cell engagement of cross-presenting microglia protects the brain from a nasal virus infection. Sci Immunol 5:eabb1817.

Nikodemova M, Kimyon RS, De I, Small AL, Collier LS, Watters JJ (2015) Microglial numbers attain adult levels after undergoing a rapid decrease in cell number in the third postnatal week. $J$ Neuroimmunol 278:280-288.

Nimmerjahn A, Kirchhoff F, Helmchen F (2005) Resting microglial cells are highly dynamic surveillants of brain parenchyma in vivo. Science 308:1314-1318.

Paolicelli RC, Bolasco G, Pagani F, Maggi L, Scianni M, Panzanelli P, Giustetto M, Ferreira TA, Guiducci E, Dumas L, Ragozzino D, Gross CT (2011) Synaptic pruning by microglia is necessary for normal brain development. Science 333:1456-1458.

Parkhurst CN, Yang G, Ninan I, Savas JN, Yates JR, Lafaille JJ, Hempstead BL, Littman DR, Gan WB (2013) Microglia promote learning-dependent synapse formation through brain-derived neurotrophic factor. Cell 155:1596-1609.

Pernici CD, Kemp BS, Murray TA (2019) Time course images of cellular injury and recovery in murine brain with high-resolution GRIN lens system. Sci Rep 9:7946.

R Core Team (2018) Statistical analysis was performed using R (version 3.4.4). Available at https://www.R-project.org/.

Rogers JT, Morganti JM, Bachstetter AD, Hudson CE, Peters MM, Grimmig BA, Weeber EJ, Bickford PC, Gemma C (2011) CX3CR1 deficiency leads to impairment of hippocampal cognitive function and synaptic plasticity. J Neurosci 31:16241-16250.

Roth TL, Nayak D, Atanasijevic T, Koretsky AP, Latour LL, McGavern DB (2014) Transcranial amelioration of inflammation and cell death after brain injury. Nature 505:223-228.

Schafer DP, Stevens B (2013) Phagocytic glial cells: sculpting synaptic circuits in the developing nervous system. Curr Opin Neurobiol 23:1034-1040.

Schafer DP, Lehrman EK, Kautzman AG, Koyama R, Mardinly AR, Yamasaki R, Ransohoff RM, Greenberg ME, Barres BA, Stevens B (2012) Microglia sculpt postnatal neural circuits in an activity and complement-dependent manner. Neuron 74:691-705. 
Schindelin J, Arganda-Carreras I, Frise E, Kaynig V, Longair M, Pietzsch T, Preibisch S, Rueden C, Saalfeld S, Schmid B, Tinevez JY, White DJ, Hartenstein V, Eliceiri K, Tomancak P, Cardona A (2012) Fiji: an open-source platform for biological-image analysis. Nat Methods 9:676-682.

Schmittgen TD, Livak KJ (2008) Analyzing real-time PCR data by the comparative C(T) method. Nat Protoc 3:1101-1108.

Sierra A, Encinas JM, Deudero JJ, Chancey JH, Enikolopov G, Overstreet-Wadiche LS, Tsirka SE, Maletic-Savatic M (2010) Microglia shape adult hippocampal neurogenesis through apoptosis-coupled phagocytosis. Cell Stem Cell 7:483-495.

Suenaga G, Ikeda T, Komohara Y, Takamatsu K, Kakuma T, Tasaki M, Misumi Y, Ueda M, Ito T, Senju S, Ando Y (2016) Involvement of macrophages in the pathogenesis of familial amyloid polyneuropathy and efficacy of human iPS cell-derived macrophages in its treatment. PLoS One 11:e0163944.

Swanson MEV, Murray HC, Ryan B, Faull RLM, Dragunow M, Curtis MA (2020) Quantitative immunohistochemical analysis of myeloid cell marker expression in human cortex captures microglia heterogeneity with anatomical context. Sci Rep 10:11693.

Tanaka R, Komine-Kobayashi M, Mochizuki H, Yamada M, Furuya T, Migita M, Shimada T, Mizuno Y, Urabe T (2003) Migration of enhanced green fluorescent protein expressing bone marrow-derived microglia/macrophage into the mouse brain following permanent focal ischemia. Neuroscience 117:531-539.
Ueno M, Fujita Y, Tanaka T, Nakamura Y, Kikuta J, Ishii M, Yamashita T (2013) Layer V cortical neurons require microglial support for survival during postnatal development. Nat Neurosci 16:543-551.

VanRyzin JW, Marquardt AE, Argue KJ, Vecchiarelli HA, Ashton SE, Arambula SE, Hill MN, McCarthy MM (2019) Microglial phagocytosis of newborn cells is induced by endocannabinoids and sculpts sex differences in juvenile rat social play. Neuron 102:435-449.e6.

Wake H, Moorhouse AJ, Jinno S, Kohsaka S, Nabekura J (2009) Resting microglia directly monitor the functional state of synapses in vivo and determine the fate of ischemic terminals. J Neurosci 29:3974-3980.

Wijesundera KK, Juniantito V, Golbar HM, Fujisawa K, Tanaka M, Ichikawa C, Izawa T, Kuwamura M, Yamate J (2013) Expressions of Iba1 and galectin-3 (Gal-3) in thioacetamide (TAA)-induced acute rat liver lesions. Exp Toxicol Pathol 65:799-808.

Xavier AL, Lima FR, Nedergaard M, Menezes JR (2015) Ontogeny of CX3CR1-EGFP expressing cells unveil microglia as an integral component of the postnatal subventricular zone. Front Cell Neurosci 9:37.

Xuan FL, Chithanathan K, Lilleväli K, Yuan X, Tian L (2019) Differences of microglia in the brain and spinal cord. Front Cell Neurosci 13:504.

Yang T, Guo R, Zhang F (2019) Brain perivascular macrophages: recent advances and implications in health and diseases. CNS Neurosci Ther 25:1318-1328. 